\title{
Small Spacecraft in Small Solar System Body Applications
}

Jan Thimo Grundmann

DLR Institute of Space Systems

Robert-Hooke-Strasse 7 28359 Bremen,

Germany

+49-421-24420-1107

jan.grundmann@dlr.de

Jens Biele

DLR Space Operations and Astronaut

Training - MUSC

51147 Cologne,

Germany

+49-2203-601-4563

Jens.Biele@dlr.de

Bernd Dachwald

Faculty of Aerospace Engineering

FH Aachen Univ. of Applied Sciences

Hohenstaufenallee 6

52064 Aachen, Germany

+49-241-6009-52343 / -52854

dachwald@fh-aachen.de

Christian D. Grimm

DLR Institute of Space Systems

Robert-Hooke-Strasse 7

28359 Bremen,

Germany

+49-421-24420-1266

Christian.Grimm@dlr.de

Caroline Lange

DLR Institute of Space Systems

Robert-Hooke-Strasse 7

28359 Bremen,

Germany

+49-421-24420-1159

caroline.lange@dlr.de
Jan-Gerd Meß

DLR Institute of Space Systems

Robert-Hooke-Strasse 7

28359 Bremen,

Germany

+49-421-24420-1206

Jan-Gerd.Mess@dlr.de

Patric Seefeldt

DLR Institute of Space Systems

Robert-Hooke-Strasse 7

28359 Bremen,

Germany

+49-421-24420-1609

Patric.Seefeldt@dlr.de

Peter Spietz

DLR Institute of Space Systems

Robert-Hooke-Strasse 7

28359 Bremen,

Germany

+49-421-24420-1104

Peter.Spietz@dlr.de

Tom Spröwitz

DLR Institute of Space Systems

Robert-Hooke-Strasse 7

28359 Bremen,

Germany

+49-421-24420-1237

Tom.Sproewitz@dlr.de

Stephan Ulamec

DLR Space Operations and Astronaut

Training - MUSC

51147 Cologne,

Germany

+49-2203-601-4567

Stephan.Ulamec@dlr.de

\begin{abstract}
In the wake of the successful PHILAE landing on comet 67P/Churyumov-Gerasimenko and the launch of the first Mobile Asteroid Surface Scout, MASCOT, aboard the HAYABUSA2 space probe to asteroid (162173) Ryugu, small spacecraft in applications related to small solar system bodies have become a topic of increasing interest. Their unique combination of efficient capabilities, resource-friendly design and inherent robustness makes them attractive as a mission element at the frontiers of exploration of the solar system by larger spacecraft as well as stand-alone low-cost approaches to open up the solar system for a broader range of interests.
\end{abstract}

The operators' requirements for cutting-edge missions compatible with available launch capabilities impose significant constraints in resources, timelines, timeliness, mass and size. To create spacecraft feasible within these constraints, the mission design teams need to accept a broad range of equipment maturity levels from fresh concepts to off-the-shelf units. The resulting Constraints-Driven Engineering (CDE) 978-1-5090-1613-6/17/\$31.00 C2017 IEEE environment has led to new methods which transcend traditional evenly-paced and sequential development. We evolved and extended Concurrent Design and Engineering (CD/CE) methods originally incepted for intitial studies into Concurrent Assembly, Integration and Verification (CAIV). It is applied in all phases in most of our projects to achieve convergence of asynchronous subsystem maturity timelines and to match parallel tracks of integration and test campaigns. When facing such a challenge, Model-Based Systems Engineering (MBSE) supports design trades and constant configuration evolution due to unforeseen changes. Proactive change and schedule acceleration has resulted from systemlevel $\mathrm{CD} / \mathrm{CE}$ optimization across interface boundaries by MBSE-aided CAIV.

We discuss advantages and constraints of small spacecraft for planetary science and applications, focusing on emerging areas of activity such as planetary defence, on the background of our projects. These include the comet lander PHILAE flown aboard 
ESA's ROSETTA probe; the mobile asteroid lander MASCOT flying on the JAXA HAYABUSA2; the mobile asteroid lander MASCOT2, a long-term stationary lander planned to land on the moon of the Didymos system, a contribution to ESA's AIM, part of the joint U.S.-European Asteroid Impact Deflection Assessment (AIDA) mission; a Jupiter Trojan asteroid lander, studied for a future JAXA Solar Power Sail mission; the GOSSAMER-1 solar sail ground deployment demonstrator of the DLR-ESTEC Gossamer Roadmap for Solar Sailing which was to enable unique and presently infeasible science missions; and its follow-on GoSoLAR which applies the deployment technology of the solar sail to ultra-lightweight very high power level photovoltaic arrays for new space mission types. We present our advanced design, integration and testing methods developed and practiced in these fast-paced highly optimized small spacecraft projects. We show why small spacecraft require big changes in the way we do things and occasionally a little more effort than would be anticipated based on a traditional large spacecraft approach. As an outlook, we illustrate how tailored concurrent methods could also benefit 'large' spacecraft and traditional methods minded spacecraft customers, and why the combination of lightweight sail and small lander can become the key to most solar system bodies currently out of reach, for planetary defence and science.

\section{TABle OF ConTents}

1. INTRODUCTION..................................2

2. EMBRACING CONSTRAINTS.....................4

3. GETTING SMALL ................................6

4. GETTING THERE ............................11

5. DOING THINGS ................................14

6. Conclusion ..................................14

REFERENCES ..................................14

BIOGRAPHY ...................................19

\section{INTRODUCTION}

Small solar system body spaceflight mission applications currently include planetary science, planetary defence, exploration, and the emerging field of asteroid mining. All of these, most pronounced for the planetary defence related missions, come in two basic categories:

First there are, prior to any recognized threat or particular interest, mainly scientific missions to investigate the properties of small solar system bodies in general.

Second, missions to characterize in specific ways, or possibly deflect or exploit, one specific object that has become a recognized threat or resource to such a degree and confidence that exclusively dedicated missions are warranted.

The main difference between those categories is that nature picks target and, regarding planetary defence, also the timeline for the latter, while for the former careful deliberation in scientific committees usually does.

\section{From Tunguska to Chelyabinsk: Bursts of Interest}

The widely reported airburst of the Chelyabinsk bolide on February $15^{\text {th }}, 2013$, returned the focus on planetary defence. This $\sim 500$ kiloton TNT-equivalent range event caused by a $\sim 20 \mathrm{~m}$ diameter chondritic body [2] was just barely non-lethal: Early reports stated that 1491 people including 311 children were seen by medical staff in the region [3] and 112 people were treated in hospitals, two of them in serious condition. One woman suffered broken vertebrae and was flown out for treatment; one man's finger was cut off by flying glass [4]. Most injuries were by glass shattered and scattered about or accelerated by the blast wave [5]. Property damage included massive destruction of window panes in the midst of the Siberian winter, mostly on appartment blocks, and several collapsed structures. [6]

The distribution of injuries also clearly demonstrated the value of preparedness in natural disasters. At one school and kindergarden site, 20 children were injured by flying glass as the blast wave hit during the break just after the first lessons were over. At another school, not recognizing the event for what it was, Ms Yulia Karbysheva, a $4^{\text {th }}$-grade school teacher, ordered her students to execute the duck and cover drill which is still customarily practised there - none of 44 was injured. She herself did not follow and suffered serious lacerations and a tendon cut by flying glass in one arm. [4]

It has to be noted that the main fragmentation occurred 31.8 $\mathrm{km}$ south of the city centre of Chelyabinsk approximately at the minimum distance to the ground track [7] at an altitude of $29.7 \mathrm{~km}$ [2], or at about $44 \mathrm{~km}$ line-of-sight distance between the largest release of energy in the event and a population of 1.13 million. Also, the most intense region of the shock wave propagating in the direction of the momentum vector originating from this area was already directed away from the city and most densely populated areas surrounding it. [8]

In the aftermath of this event, the size-frequency distribution of natural impactors at Earth and their potential for destructive effects on the ground, and technical options for near-Earth object (NEO) deflection were revisited extensively. [9]

The first wave of attention to the NEO threat had recognized the rare but potentially globally catastrophic impacts of kmsized near-Earth asteroids (NEA) based on early photographic asteroid surveys and the cratering record of Earth. It drew strongly on prehistoric indicators of major impacts, e.g. the iridium anomaly at the cretaceous-tertiary boundary in the seminal Alvarez hypothesis [10]; the recognition of Meteor Crater near Flagstaff, Arizona, [11] of the Tunguska event of 1908, [12] and other related records, e.g. [13] for a historical summary. Recognition of the impact threat was formalized into the goal to discover $90 \%$ of all NEAs larger than $1 \mathrm{~km}$ diameter, relatively quickly followed up by the definition of Potentially Hazardous Asteroids (PHA) of at least $140 \mathrm{~m}$ diameter which can 
approach Earth to within 0.05 AU. Current NEO surveys [14] confirm the significant contribution to the threat of the much more frequent small impactors with regional or locally devastating effects. [15] NEAs in the sub-PHA size range have recently become sufficiently accessible to observation to enable population estimates based on rediscovery rate which indicate that their relative frequency is somewhat higher than previously expected [16][17][18]. U.S. government sensors recorded at least 556 fireball events from 1994 through 2013, ranging from about 5 ton TNT-equivalent to the Chelyabinsk superbolide. [22] Also, modelling of atmospheric entry fragmentation strongly suggests much higher yield to ground-level damage efficiency than previously expected from observations made e.g. at the 1908 Tunguska impact site. [19][20][21]

Recognition of the threat posed by smaller, more frequent impactors also changed the mitigation approach. The impulse necessary to deflect an object on a given orbit to a safe passage of Earth is proportional to its mass - a substantial reduction of requirements for the expected likely next event. The unlikely surprise civilization killer asteroid scenario was relegated by impacts just slightly too large to be dealt with by practical application of preparedness and existing civil defence infrastructures but likely to occur on human timescales. For yet smaller impactors, the choice is to duck and cover or to stand and stare - and invite friends.

The lasting success of NEO surveys is the reappreciation of risk focused on likelihood of occurrence on human timescales. It made deflection feasible within the present capabilities of the Earth's spaceflight infrastructure. However, smaller impactors are also much more difficult to detect. First-generation NEO surveys reliably detected kmsized objects nearby but tracking them at distance was a challenge. Thus, early end-to-end mitigation concepts focused on large detectable objects at short warning lead times. Correspondingly challenging large space segments were required for mitigation. Acceptance of the risk posed by the much more frequent Tunguska-sized impactors catalyzed significant improvements of global NEO observation and tracking capabilities. This greatly increased the likely lead time at which a reliable positive prediction of impact can be made; cf. [23] and references therein.

The earliest space-based planetary defence scenarios envisaged nuclear payloads of unprecedented size to be put on the largest launch vehicles ever built - and long since decommissioned - for launch on very short warning lead times. [24] Now, flight hardware derived from recently flown and currently developing interplanetary missions can meet mitigation mission requirements on timelines of several years to a few decades from discovery to arrival at the target NEO. If applied in a timely manner, advanced methods of deflection e.g. [25][26][27], can eliminate the need for nuclear mitigation and the justified concerns regarding its use (cf. [23][28][102][103]) for all but the very largest at all possible impactors. Concurrently, advanced NEO surveys approach completion of their inventory, eliminating the residual risk of surprise in this size segment [15].

\section{From Hammer to Ore: The Rise of Space Resources}

Most recently, commercial interest in the exploitation of SSSB resources in space has emerged. As a fresh field, 'asteroid mining' is currently in a process of analysis and concepts definitions, surveying and prospecting related fields of science and engineering. The legal framework is of particular importance to the commercial stakeholders; it consists of existing space treaties, national space legislation, and analogies to deep-sea mining or the status of Antarctica. [104] On the technical side, mission and techology concepts definition is in the process of studying the asteroid surroundings, surface and subsurface environments as well as links with planetary science, exploration and planetary defence. Experience from similar terrestrial activities in extreme environments on Earth, e.g. deep-sea mining, is also reviewed. [105] Current activities are very much remeniscent of the early days of workshops evolving into Planetary Defence Conferences and sessions at comprehensive space-related conferences.

\section{The Missing Link: SSSB Science as a Service Provider}

Science missions do not fly frequently. Thus, science output and consequently launch mass is typically maximized to the limit of accessibility of any suitable target object for affordable launchers within the space agency mission class. Conversely, for threat-related planetary defence missions, the only constraint is the target object itself including getting there in time. Mining-related missions would likely aim for an economic balance in-between, of effort to access and gain to be achieved, but are also likely to be significantly constrained by some properties of the object(s) of interest. Also, a rigidly streamlined mission and hardware design can be expected as the business case "requires the payload customer to separate "desirements" from "requirements" and be willing to trade-off the former to prevent intolerable increases in cost and schedule.' [106]

For science missions, the target object can become a constraint on the scientific mission concept. Many interesting objects are difficult to reach without curtailing mission scope in favour of propulsion and/or greatly extending flight time by planetary gravity-assists. However, this only prevails as long as interest in a specific object or a subset of possible targets outweighs more general considerations of the scientific communities involved in the mission. In most cases, a more easily accessible object of the same or a sufficiently similar class would be selected. There may however be missions for which just one object of the vast number of solar system bodies discovered so far is of interest and accessible at the same time. [1]

Conceptually, there is a very wide overlap of interest and methods and technologies of these three small solar system body application fields, gaining knowledge and exploring resources and safeguarding our home planet. But most importantly, small solar system body planetary science 
understood as anything advancing beyond pure positional astronomy to explore the properties of the objects themselves is the root of all fresh branches of applications. There necessarily is a wide arena of common interest which can become a gateway of mutual productive and proactive interaction. For science as an entitiy fundamentally independent of specific business interests to provide comprehensive knowledge on SSSBs and to participate in the study of specific objects of commercial interest with proven instruments to expand this knowledge. For miners to benefit equally from open literature in the pursuit of specific interests and already developed equipment, and to create interest in and open up new fields of science which have not yet been studied. For planetary defence, there already is an established exchange with SSSB science which can serve as a template for the interaction of both with the new field of mining. It has led to the rapid progress of NEO surveys, outpacing many traditionally growing fields of astronomy, yet giving them ample and valuable bycatch particularly in any kind of transient phenomena. Now, it is about to continue into spaceflight on a global scale in the form of the joint U.S.-European Asteroid Impact Deflection Assessment (AIDA) mission. [107]

\section{EMbracing CONSTRAINTS}

Whether it comes to a recognized threat situation which ties planetary defence related missions to one specific object, or whether a wider choice of target objects for scientific missions or mining prospection is desirable - there are two basic fundamentals of spaceflight to improve performance:

First, reduce spacecraft mass by designing merely the best mission possible into the envelope of constraints ultimately driven by the object of interest, within the capabilities of the present spaceflight infrastructure; that is, decide to accept significant constraints beyond those which would commonly apply to an otherwise similar science mission and then stick to them.

Second, improve the $\Delta \mathrm{v}$ of the spacecraft after launch from Earth; that is, decide to add propulsion-related functions to the spacecraft and to accept advanced or new technologies into such key functions to mission success, under mission responsibility.

\section{Current Science Missions: Application of Pure Method}

The first way out is none less than a paradigm shift in spacecraft design procedures.

Scientific interplanetary missions are presently developed according to established agency and industry procedures and standards in a more or less linear fashion. A mission is derived from a basic set of stakeholder requirements that has already come out on top in a competitive peer-reviewed selection process. In a development process divided up into phases ranging from mission concept definition to hardware integration, those requirements are successively devolved or branched out to the next levels of detail from where in turn every detail requirement is traced back to the previously established higher levels for its justification. These levels, and therefore the justification of all following levels of finer detail, are confirmed by major reviews at least once at every phase transition, become frozen, and thus form the baseline design for the next phase. During testing, all previous connections of requirements are similarly retraced for the purpose of verification of fulfillment.

Both processes inherently work as one-way roads. The requirements-driven technical design process lets the design expand from any given initital concept or current baseline into a generally open and unconstrained design space, but only within the limits of detail defined by the current project phase. The phased management of development leads to the creation of a succession of consolidated baseline designs from which the next phase or design cycle sets out. Each step in this succession of baselines needs to be formally certified by review to become frozen and thus allow the design to proceed. Technical as well as managerial work is commonly carried out in compartimentalized work packages with defined interfaces of data exchange and hierarchical communication which require formal data release processes.

The division of work is often paralleled with contractual divisions of labour and contractual implications to be considered in the exchange of design data between the technical staff dealing with the purely technical content of the work packages, e.g. when some specific subset of the design data is not explicitly covered by the related contracts and/or intellectual property issues arise. In almost all cases work is carried out at widely separated sites for programmatical and other reasons. Change, which is mostly externally driven (e.g. by programmatic guidance, limitations or reorganization) can only be accommodated by going back to an earlier baseline and restarting development as a whole from there; in the extreme, though by no means rarely, effectively going back to start from scratch in the middle of an established major project. Often, when corrections or changes only apply to a subset of domains, other work packages have to idle until a common level of maturity and/or formal state of phased development is regained. Such change processes have to be implemented with care to ensure that every lane of communication is formally updated to the new baseline which is then not just a refined derivative of the previous one.

\section{Constraints-driven Design: Small Organic Integrated}

A planetary defence related mission can be expected to be developed in reaction to a small target Near-Earth Object (NEO) which is in some way newly discovered $[14][15][16][29]$. In the broader sense, mission and spacecraft design acts in response to a mission target or objective that with the ongoing initial accumulation of knowledge on it poses fluid requirements, possibly until launch and thereafter. In this case, development can easily find itself between the hard natural constraint of timely accessibility of the physical target and the artificial constraints created by the phased requirements-driven 
development method that most in the industry and government agencies are used to. The accessibility of the target is defined by the laws of orbital mechanics, available launch and communication capabilities, and in the case of deflection also by the efficiency and timing of the selected method for impulse transfer. [25] Considering NEO accessibility studies related to science missions with comparatively stringent target selection constraints, e.g. [1], it appears quite likely that any other artificial burden beyond those imposed by nature and the serendipity of discovery could over-constrain such missions into infeasibility.

Efficient accommodation into an environment which poses a challenging and changing target definition however requires more than occasional re-tracing, tailoring or redefinition of requirements on paper. Even fundamental assumptions that would normally constitute long frozen and elementary mission requirements may have to be questioned rather frequently based on the need to maintain mission feasibility, immediately affecting the implementation of design or hardware production that follow from them. At later stages, changes may have to be implemented without the time to change hardware that already had to be produced due to lead times. Also, the design has to flow constantly into the possibly also changing - constraits envelope related to a timely launch. These may, for example, be as simple as very clear cut limits of mass and geometrical size which immediately follow from launch vehicle capabilities and from the interplanetary transfer orbit that also sets the timeline to a fixed launch window. As soon as the spacecraft mass and size is constrained to limits below those of comparable mainstream science missions the design becomes fundamentally constraints-driven and requires overall optimization and organic integration to enable the maximum possible mission. This need for thorough optimization thus blurs the interface boundaries of technical subsystems as well as the organizatorial structure and work package divisions. Also, since the efficiency of thorough optimization can depend on the implementation of relatively minor details, particularly when close to functional interfaces relevant for organic integration, attention to detail cannot be postponed until the appropriate project phase: The earlier hardware implementation can be exercised and tested, the more design space within the envelope of constraints is liberated from margins allocations by detailed knowledge and understanding of the design. Similarly, it is very unlikely that resource allocations defined at an early stage can be upheld simply because the blanket application of a structured margins philosophy (e.g. [30]) may already overconstrain the design. Every subsystem needs to be optimized as far as possible within the given timeframe, not just enough to pass under its allocation limits.

All this sounds very inconvenient to the user of established standard methods of spacecraft design, often to the point of 'you can't do that's. But it all is characteristic of small spacecraft and common practice in their design, latest when that leaves the paper stage. Particularly those which can only affordably get into orbit as secondary or tertiary payloads by sharing a ride with other, usually much larger spacecraft reach a point of no return to requirements-driven design when they have to convert to a significant level or fraction of constraints-driven design. For these, the main passenger of the launch acts as the authority to set effectively immovable constraints. These effectively define feasibility of the small spacecraft's design and mission concept, on the background of programmatic infeasibility of procurement of a dedicated launch of their own for the smaller payloads.

Once such a small spacecraft mission has reached sufficient maturity to be manifested into the spare capacity of a launch, also the launch window becomes fixed, at least relative to the progress of the main payload. Launch dates for Earth-orbital missions are known to slip considerably from the envisaged date at gaining funded project status till actual launch. But manifestation of the launch occurs only 12 to 18 months before the set launch date at that stage of the prime payload project, and secondary passengers are often only admitted later. This leaves about two years from the start of serious launch negotiations and about one year from a confirmed but by no means guaranteed launch opportunity to commit expensive, expirable and/or long lead time hardware to spacecraft integration and qualification, and get ready for launch. Margins are commonly in the not unlikely delays of a few weeks to months for key dates within this launch manifestation timeframe - but they may as well be zero.

These project conditions are about as poles apart as possible from mainstream interplanetary science mission project environments. But they are also currently the best approximation in living spacecraft design experience to the likely situation of threat-related planetary defence missions. Here, the tightest project timelines can be expected for the early precursor reconnaissance missions necessary to understand the potential Earth impactor as soon as possible before committing to or finalizing the flight hardware of possible deflection missions.

\section{Propulsion: Beyond Hydrazine and Fly-by}

The second way, improvement of overall delta-v, offers a growing choice of reasonably developed propulsion methods, from simply larger fuel fractions to 'alternatives' such as electrical propulsion. However, alternative methods, i.e. any other than storable chemical propellant based thrusters and the use of planetary gravity assists, are only slowly and 'from below' entering the segment of science missions, cf. [131]. Often, these are primarily technology demonstration missions which are adapted to a planetary science objective to demonstrate compatibility of a new technology with science missions in general and their required quality of results. Early examples were the $373 \mathrm{~kg}$ DEEP SPACE 1 (DS1) which visited asteroid (9969) Braille and comet 19P/Borelly using solar-electric ion propulsion of $2.1 \mathrm{~kW}$ power [31][32][33], the $367 \mathrm{~kg}$ European Moon probe SMART-1 (Small Missions for Advanced Research in Technology) which used a solar-electric Hall effect thruster 
of $1.2 \mathrm{~kW}$ to raise its orbit from the initial geostationary transfer orbit (GTO) to capture into lunar polar orbit [34], and the first successful asteroid sample return by the $510 \mathrm{~kg}$ Japanese probe HAYABUSA using solar-electric xenon ion engines [35][36]. For the largest science missions, the transition towards electric propulsion is only beginning: $56 \%$ of the launch mass of the CASSINI-HUYGENS and MESSENGER (Mercury Surface, Space Environment, Geochemistry, and Ranging) spacecraft, each, was chemical propellant, but only $34 \%$ of BEPICOLOMBO of which more than half is xenon for solar-electric propulsion. [37]

\section{Large Lightweight Deployables: Photovoltaics and Sails}

The obvious next step is the use of large-area structures, either to generate more photovoltaic power for solar-electric propulsion or to employ solar sails. A solar power sail has been proposed by the Japan Aerospace Exploration Agency, JAXA, for a Trojan asteroid sample-return mission [38][130] following the successful solar sail demonstrator IKAROS (Interplanetary Kite-craft Accelerated by Radiation Of the Sun) which was launched as a secondary payload with the Venus Climate Orbiter (VCO) probe, AKATSUKI. [39][40][41] Although by unusual launch circumstances and requirements not mass-limited but required to have a comparatively high minimum mass, IKAROS can be considered a small spacecraft in this context due to the way it was instituted as a mission, designed and built. [42]

\section{Getting SMall}

This section provides a brief overview of the recent projects and activities at DLR. All these are either scientific missions to small solar sysem bodies or technology demonstrators. With respect to planetary defence, DLR at the Institute of Planetary Research also led the NEOShield Project, funded by a $7^{\text {th }}$ Framework Programme (FP7) grant from the European Commission (EC) [43].

\section{PHILAE - landed and found}

RosetTA was a Cornerstone Mission of the Horizon 2000 ESA Programme. The mission was launched in 2004 and reached its target, comet $67 \mathrm{P} / \mathrm{Churyumov-Gerasimenko} \mathrm{in}$ 2014. [44][45] After an intense phase of remote investigation of the comet nucleus including the selection of an appropriate and safe landing site, Agilkia, in mid-2014 the Rosetta Lander, Philae, (Fig. 1) performed the first ever landing on the surface of a comet on November $12^{\text {th }}$, 2014. [46][47] It has an overall mass of $98 \mathrm{~kg}$, carrying 26.7 $\mathrm{kg}$ of science payload in a carbon fibre / aluminium honeycomb structure. The power system includes a solar generator, primary and secondary batteries. The central data management system communicates by S-band, using the RoseTTA Orbiter as relay. During cruise the Lander has been attached to the Orbiter with the MSS (Mechanical Support System) which also includes the push-off device, separating PHILAE from the Orbiter. [48][108][109] In this vantage position it was able to support RoSETTA during critical phases such as the Mars fly-by and while the comet

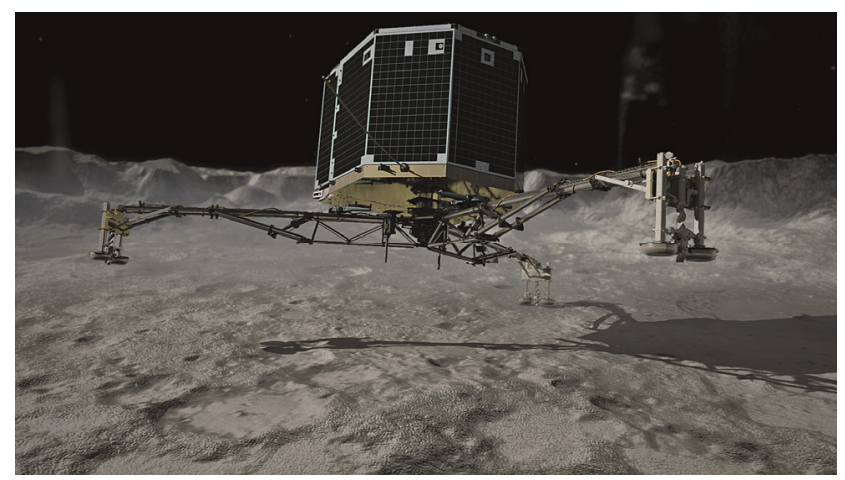

Figure 1: PHILAE before a touch-down (artist's concept)

was out of view of the boresighted mothership instruments (Fig. 2). It also monitored the deployment status of the photovoltaic arrays for ROSETTA's aphelion hibernation.

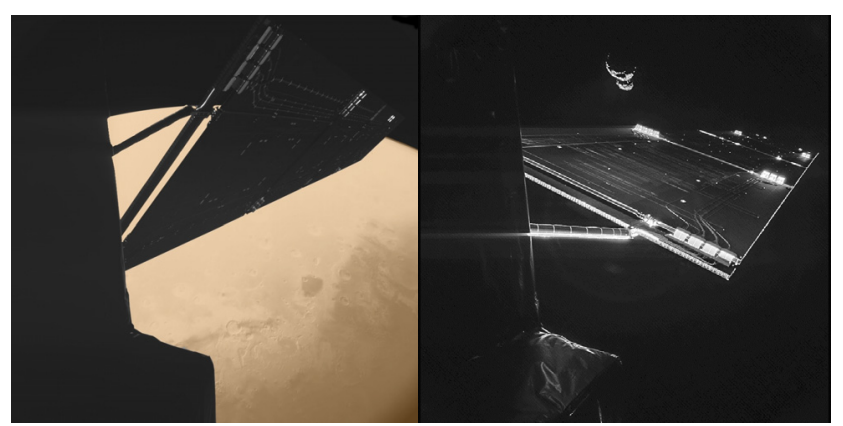

Figure 2: Worlds viewed from a small spacecraft's perspective - Mars and 67P/Churyumov-Gerasimenko C ÇIVA/PHILAE/RosetTA/ESA

The selected landing scenario foresaw separation at an altitude of $20.5 \mathrm{~km}$. The descent to the surface took just under 7 hours, as expected. At touch-down anchoring harpoons were to be fired and a cold gas system should have prevented re-bouncing while ice screws were expected to drill into the surface to secure PHILAE in place [49][50]. However, after touchdown at its intended landing site, Agilkia, on 67P/Churyumov-Gerasimenko on November $12^{\text {th }}, 2014,15: 34$ UTC, the lander immediately bounced off again, since the anchoring harpoons did not fire and the cold gas system did not provide hold-down thrust. PHILAE finaly came to rest at a heavily shadowed site now called Abydos where it successfully conducted scientific measurements until all energy was depleted on November $15^{\text {th }}, 2014,00: 07$ UTC. [51]

During a first scientific sequence on the comet of 57 hours, PHILAE was powered mostly by its primary batteries helped by the initial charge of the secondary batteries and some photovoltaic input. Several instruments and subsystems were operated simultaneously. Each experiment was operated at least once.

The expected long term operations phase foresaw the experiments to work mainly in sequence, one by one and to be scheduled according to power, energy availability and 
data relay capacity. In this phase, data evaluation was expected primarily offline, while pre-planning activities were to be performed in parallel; with various experiment operations for up to a few months on the comet surface. Expectations were low after the unexpected events upon landing(s) but telemetry from PHILAE was received again on June $13^{\text {th }}, 2015,20: 28$ UTC showing that it had been intermittently active already since May. Signals were received sporadically till July $9^{\text {th }}$, but even including attempts of 'blind commanding' and an adaptation of ROSETTA's orbit to impove radio visibility and distance, regular operation could not be established. [110] The communication conditions with ROSETTA have been unfavourable until recently because the orbiter had to retreat from the core of comet $67 \mathrm{P} /$ Churyumov-Gerasimenko due its much increased activity near perihelion. As this activity subsided, ROSETTA approached it again, mainly for close-up studies of the nucleus, but also prepared for a possible second phase of science activities of PHILAE on the surface. [52] In the last month of the mission before RosETTA itself was to be beached on 67P, PHILAE was located by close flyby photography of the landing area, wedged in between rocks.

PHILAE represents the first time that a lander, though in itself a complete spacecraft, and not a small one at that, is not the driving element of the main mission; here in that it was not considered essential before the call for proposals for instruments to fly aboard ROSETTA. The concept of integrating a small spacecraft style lander at the instrument level of the mothership mission has since been repeated by BEAGLE 2 on MARSEXPRESS, and the target markers, various MINERVAs and MASCOT on the HAYABUSA missions.

\section{MASCOT - a Constraints Envelope come Alive}

In the last few years, DLR has developed the Mobile Asteroid Surface Scout, MASCOT, a small asteroid lander which packs four full-scale science instruments (Fig. 3) and relocation capability into a shoebox-sized $10 \mathrm{~kg}$ spacecraft. It carries the near-IR soil microscope, MicrOmega, (MMEGA), [129] a high dynamic range black-and-white camera with night-time multicolour illumination (CAM), [126] a 6-channel thermal IR radiometer (MARA), [127] and a fluxgate magnetometer (MAG). [128]

The Flight Model (FM, Fig.16) was delivered to JAXA midJune 2014. It was launched aboard the HAYABUSA2 space probe on December $3^{\text {rd }}, 2014$, and appeared in good health at its first activation 2 weeks later. In June 2015, the first inflight calibration session was completed successfully. In September 2015, the launch Preload Relief Mechanism was successfully actuated, putting MASCOT in a separationready configuration. Passing by Earth once more in late 2015 for a gravity-assist, HAYABUSA2 is carrying MASCOT along to asteroid (162173) Ryugu (formerly $1999 \mathrm{JU}_{3}$, [53]) using solar-electric propulsion. MASCOT, following constraints set by its mothership and target asteroid, is an organically integrated high-density design.
$[54][55][56][57][58][59]$ MASCOT's structure is a highly integrated and ultra-lightweight truss-frame made from a CFRP and Rohacell ${ }^{\circledR}$ foam sandwich. [60][61]

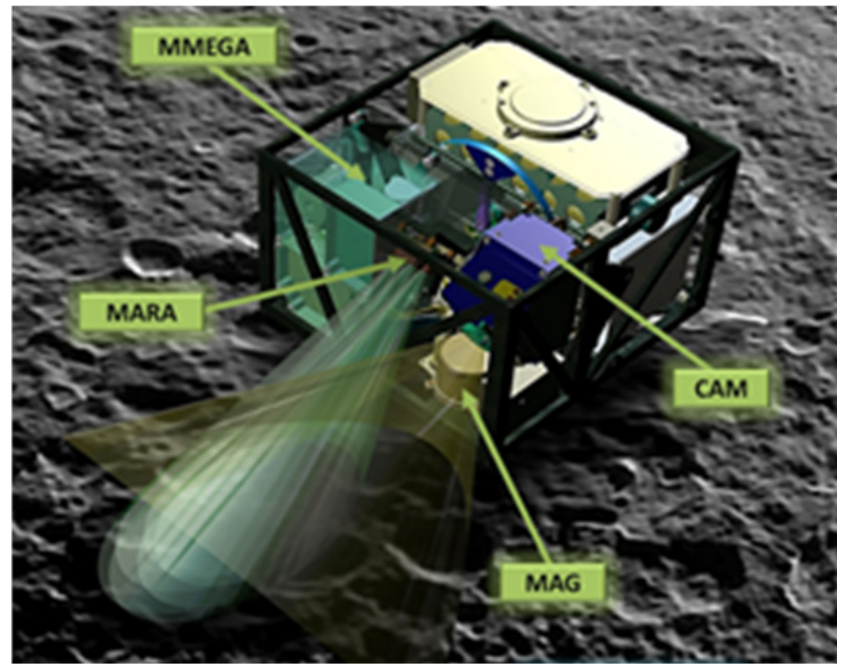

Figure 3: The MASCOT Lander and its science instruments operating on the asteroid, outer single layer insulation foil not shown for clarity, cf. Figures 14 \& 18

It has three internal mechanisms: i) the Preload Release Mechanism to release a controlled $\mathrm{kN}$-range preload in the structure and across the separation mechanism interface which suppresses detrimental vibrations; ii) the Separation Mechanism to realize the gentle push-off of MASCOT at $\sim 5$ $\mathrm{cm} / \mathrm{s}$ out of the Mechanical Support Structure, MESS, recessed inside the HAYABUSA2 envelope; and iii) the Mobility Mechanism for uprighting and hopping across the asteroid surface over distances from less than a metre up to $220 \mathrm{~m}$. [62] MASCOT uses a semi-passive thermal control concept, with two heatpipes, a radiator, and Multi-Layer Insulation (MLI) for heat rejection during active phases, supported by a heater for thermal control of the battery and the main electronics during passive phases. [63] During its on-asteroid operational phase, it uses a primary battery as power supply. During cruise, it is supplied by HAYABUSA2. The Power Conversion and Distribution Unit (PCDU) applies a mixed isolating/non-isolating conversion concept adapted to grounding within a nonconductive structure. [64] All housekeeping and scientific data is sent to Earth via a relay link with the HAYABUSA2 main spacecraft using redundant UHF-Band transceivers and two patch antennae on either side of the lander, with omnidirectional coverage. The MASCOT On-Board Computer (OBC) is a redundant system providing data storage, instrument interfacing, command and data handling, as well as autonomous surface operation functions. The operational redundancy mode is configurable in a four module set of two CPUs and two I/O and mass memory boards to optimize power consumption and robustness on the background of an exclusively primary battery powered mission. Knowledge of the landers attitude on the asteroid is key to the success of its uprighting and hopping function. The attitude is determined by a threefold 
set of sensors: optical distance sensors, photo electric cells and auxiliary as well as experimental thermal sensors.

Looking at current planning for SSSB-related missions to in the next years, it is apparent that flight opportunities will arise for such a small versatile add-on landing package to complement and enhance the main mission's objectives at a comparably low cost.

This is why at DLR, we are using our knowledge [65] to build on this heritage by carrying forward the idea of further MASCOT derivatives. Such derivatives or variants will be differing in their main features such as lifetime (long-lived vs. short-lived), feasible landing velocity (small or high velocity landing) or instrument suite (e.g. radar tomography vs. geology vs. geochemistry), but will all be based on a common platform. [66] The main goal is to advance the current design from the dedicated lander MASCOT, to a generic instrument carrier able to deliver a variety of payload combinations on different mother-missions to different target bodies. To minimize the effort of redevelopment and the time to obtain a new design, we are employing principles of Model Based Systems Engineering (MBSE) [67] and Concurrent Engineering [68][69][70].

\section{GOSSAMER-1: "So hoist the foil and booms..."}

The Gossamer-1 large lightweight structures and solar sail deployment technology demonstrator has recently completed its qualification testing at DLR Bremen.

The idea of an outward propulsive force of sunlight goes back to Kepler's observations and remarks published in 1619 on the directionality of comets' tails [71]. It was predicted to equal magnitude in 1873 by Maxwell on the basis of his electromagnetic theory [72] and in 1876 by Bartoli based on the Second Law of Thermodynamics [73] but could only be experimentally demonstrated as pressure due to radiation by Lebedev in 1901 [74] and by Nichols and Hull in 1903 [75].

The development of solar sail technology has been ongoing at DLR at varying levels of intensity since the 1990s. A first

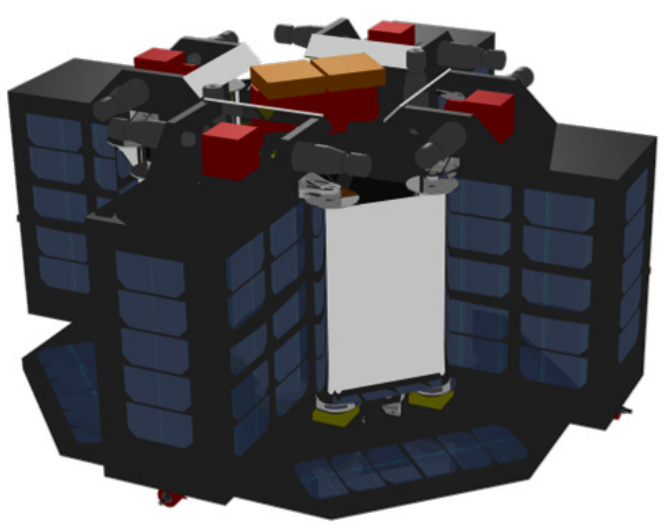

Figure 4: GosSAMER-1 solar sail deployment demonstrator configuration for low Earth orbit phase culminated in a successful ground deployment test of a $(20 \mathrm{~m})^{2}$ boom-supported sail on December $17^{\text {th }}, 1999$. [76]

In its solar sail application, the GOSSAMER-1 deployment demonstrator (Fig. 4) was originally intended as the first step in the DLR-ESTEC GOSSAMER roadmap [77], leading to practical sailcraft of sizes enabling unique science missions that are presently difficult to achieve or not feasible using other post-launch propulsion methods. Among these mission types, three were studied in detail: i) a multiple NEO rendezvous (MNR) mission with the capability of additional fly-bys between stays at 3 NEAs within 10 years of flight time [78], recently achieving 5 NEA rendezvous of 100 days, each, in the same time with a less performant sail (Fig. 5) [111]; ii) a Displaced-L (DL1) $^{2}$ spaceweather mission which bears some similarity to a coorbital NEA rendezvous flight profile [79]; and iii) a Solar Polar Orbiter (SPO) mission which bears some similarity to a highly inclined and eccentric orbit NEA rendezvous flight profile [80]. All these missions are small spacecraft that could ride as secondary payloads, to GTO to proceed from there with a small kickstage, or to high circular orbits or $\mathrm{L}_{1} / \mathrm{L}_{2}$, to sail out. They are all within the capabilities of currently available sail film and boom technology, [81] much of which is now qualified. [113][114][115][117]

One advantage of solar sailing is the relative ease of target object change during the mission. It would for example be possible to re-direct a multiple NEO rendezvous mission similar to [78][111] to a newly discovered target of urgent interest or change the priority of target objects when the progress of science or other missions makes this desirable. Some flexibility of this kind is, within the limits of fuel and

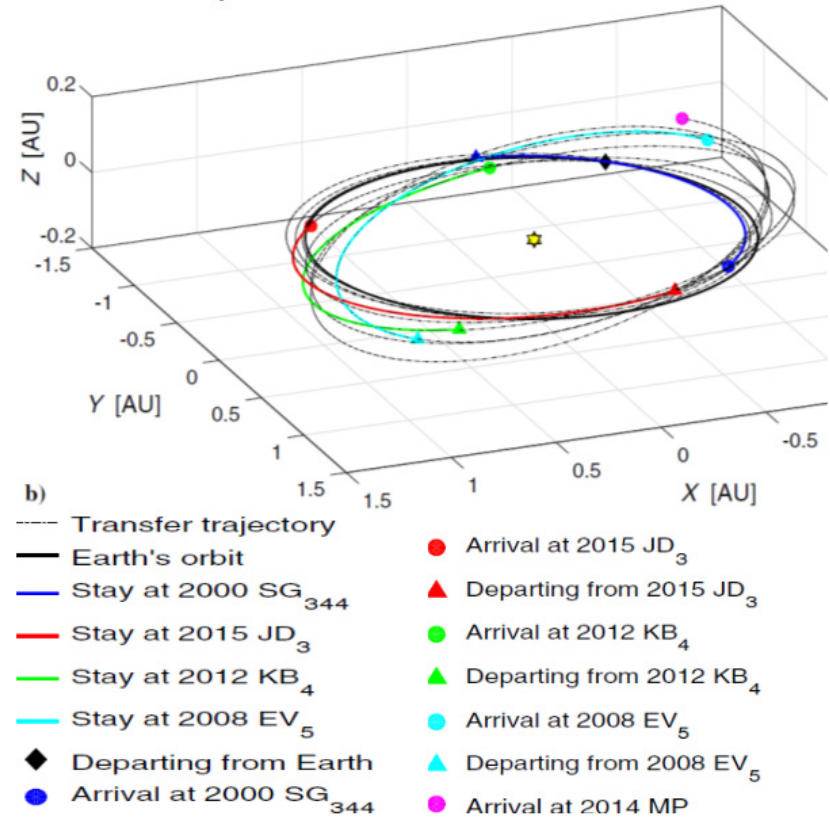

Figure 5: Near-term sailcraft Multiple NEA Rendezvous mission visiting within 10 years for at least 100 days, each, the NHATS NEAs $2000 \mathrm{SG}_{344}, 2015 \mathrm{JD}_{3}, 2012 \mathrm{~KB}_{4}$, $2008 \mathrm{EV}_{5}$ (PHA), and $2014 \mathrm{MP}$ - adapted from [111] 
photovoltaic power, also possible for some lightweight solar-electric missions, as was shown e.g. by the target object changes of DEEP SPACE 1 throughout its project and flight history. Also, the adaptation of the cruise trajectories of HAYABUSA was only possible due to advanced propulsion capabilities, as is the double rendezvous of DAWN with the two largest main belt asteroids, (4) Vesta and (1) Ceres. Among other uses closer to Earth, this has generated interest in high power electric propulsion for which very large lightweight deployable structures seem attractive for photovoltaic supply. [38][40][81]

However, the unique capability of accelerating without having to consume or carry propellant that is characteristic of solar sailing remains a mission enabler for high $\Delta \mathrm{v}$ and hypervelocity missions beyond the range of any fuel-based propulsion method. [82][83]

A number of projects at DLR and other institutions have already re-used technology developed for GOSSAMER-1. E.g. the Bluetooth ${ }^{\circledR}$-based networking concept used between the Central Sailcraft Unit (CSCU) and the four Boom Sail Deployment Units (BSDU) and their computer design have already been carried on to the network of Remote Units and Lander of the lunar analog demonstration mission of the ROBEX Alliance [118] which successfully passed a first field test in September 2016 on the flanks of Mt Etna. [119]

\section{GOSOLAR - Large Lightweight Photovoltaics}

After the termination of the GOSSAMER-1 project at the end of 2015 , the team and its experience seamlessly continued into our new project, GoSOLAR. The focus is now entirely on gossamer deployment systems for huge thin-film photovoltaic arrays. [112] Based on the previous achievements in the field of deployment technology and qualification strategies (Fig. 6), new technology for the integration of thin-film photovoltaics is being developed and will be qualified for a first in-orbit technology demonstration expected to achieve flight readiness within about five years. The two major objectives of the project are the further development of deployment technology with adaptations for a $(5 \mathrm{~m})^{2}$ gossamer solar power generator and

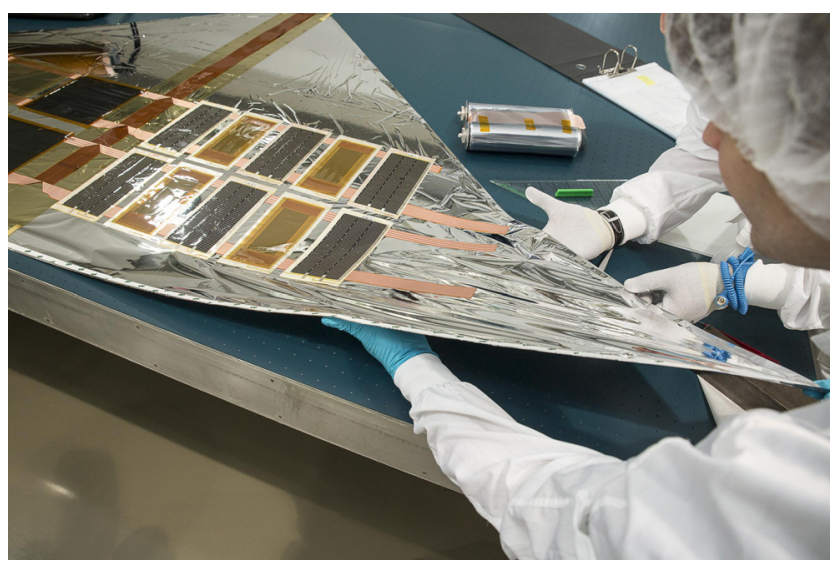

Figure 6: Thin-film photovoltaics on the sail foil - [113] the development of a flexible photovoltaic membrane. The technology demonstration is slated to employ the $\mathrm{S}^{2} \mathrm{TEP}$ bus system which is developed on-site in parallel. [116] The technology is envisaged to be scalable to $(20 \mathrm{~m})^{2}$ and more, providing 10 's to 100 's $\mathrm{kW}$, mainly for solar-electric propulsion which plays a prominent role in all SSSB applications. Once at the asteroid, the power can be used for deflection [26][27] as well as mining equipment.

\section{AIDA - Combined Operations}

The Asteroid Impact \& Deflection Assessment (AIDA) mission is planned as the first space experiment to demonstrate asteroid impact hazard mitigation by using a kinetic impactor to deflect an asteroid. AIDA is a joint NASA-ESA mission in pre-Phase A study, which includes the NASA Double Asteroid Redirection Test (DART) mission and the ESA Asteroid Impact Monitor (AIM) rendezvous mission. The primary goals of AIDA are first to test our ability to impact a small near-Earth asteroid by a hypervelocity projectile and second to measure and characterize the deflection caused by the impact. [107]

The AIDA target will be the binary asteroid (65803) Didymos, with the deflection experiment to occur in October, 2022. The DART impact on the secondary member of the binary at $\sim 6 \mathrm{~km} / \mathrm{s}$ will alter the binary orbit period, which can be measured by Earth-based observatories. The AIM spacecraft will monitor results of the impact in situ at Didymos. AIDA will return fundamental new information on the mechanical response and impact cratering process at real asteroid scales, and consequently on the collisional evolution of asteroids with implications for planetary defense, human spaceflight, and near-Earth object science and resource utilization. The AIM component of AIDA has also been studied in variations of spacecraft and payload sizes for different classes of launch vehicles which would enable the accommodation of landers within a size range approximately between MASCOT and PHILAE on instrument level, where in the latter's envelope a number of smaller landers could be carried as an alternative. [84]

DLR is currently applying MASCOT heritage and lessons learned to the design of MASCOT2, a lander for the AIM mission to support a bistatic low frequency radar experiment with PHILAE/ROSETTA CONSERT [85] heritage to explore the inner structure of Didymoon which is the designated impact target for DART. The current MASCOT2 baseline design envisages (Fig. 18) only the minimum of modifications necessary to adapt the short science mission lifetime optimized design of MASCOT at HAYABUSA2 to a long-life photovoltaically powered mission more similar to the once envisaged extended operations phase of PHILAE. Also, some modifications necessarily follow from changes in the suite of instruments of which only some are expected to be re-used from the first MASCOT. The fundamental changes in the power supply and instruments concept have lead to some growth but it remains well within the margins to be applied on top of the respective original MASCOT's parameters for a partially new, partialy modified design. 
[30] However, the basic constraints-driven design and concurrent engineering approaches characteristic of MASCOT seem set to be continued due to the resources envelope constraints and timeline requirements of the AIM mission. [86]

\section{Everyone's Favourite MASCOT}

The attention caused by the coincidence of PHILAE's landing(s) and MASCOT's launch in late 2014 resulted in a whole host of small SSSB lander studies at DLR. They range from spacecraft considerably smaller and somewhat simpler than MASCOT to fully PHILAE-sized and even more complex and ambitious robotic laboratory stations, e.g. the JAXA-DLR study of a sample-return lander for the JAXA Solar Power Sail; [130] and from 1:1 or 'tactical' re-use [83] to entirely new designs with more subtle re-use of MASCOT and PHILAE design features at unit level. However, as demonstrated by the work on MASCOT2 for AIM, the original MASCOT design appears quite well prepared for strategic re-use [87] even though this was not an important factor during its design phase which out of necessity built on concepts of successively smaller derivates of PHILAE [47]. One key feature is shared by all these fresh branches on the MASCOT family tree: they are selfcontained spacecraft integrated at the instrument level from the perspective of their respective mothership missions.

\section{ASTEROIDFINDER - Breaking the Sunlight Barrier}

In 2008, DLR selected the AsteroidFinder Instrument (AFI) to be studied extensively for a mission on the satellite platform being developed at the time in the frame of the German national 'Kompaktsatellit' (compact satellite) Program. The scientific goal was to contribute to the understanding of the dynamical evolution and the cratering history of the innermost region of the Solar System, and the assessment of the impact hazard posed by objects Interior to Earth's Orbit (IEOs). Also called Inner Earth Objects, Apohele or Atira asteroids, these NEOs' orbits are completely contained within the Earth orbit's perihelion distance, $0.983 \mathrm{AU}$. If at all, IEOs are only observable from

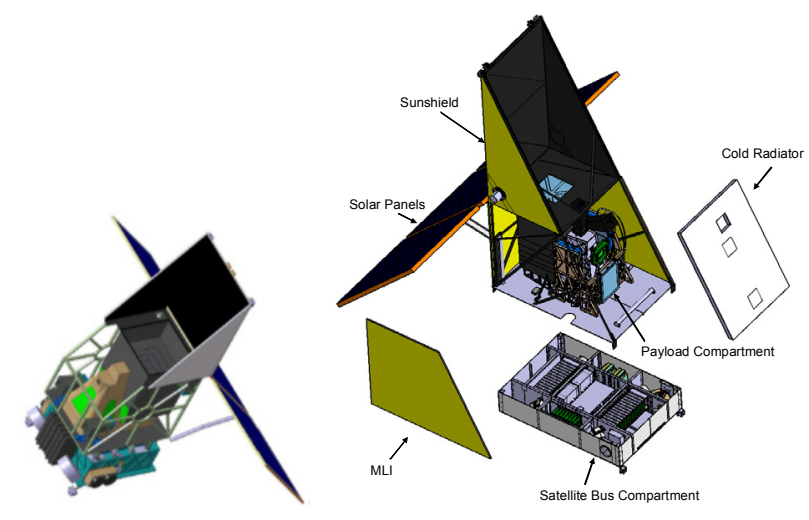

Figure 7: ASTEROIDFINDER - left: secondary payload envelope configuration, /SSB, with deployable sunshield; right: final dedicated launch design with fixed sunshield the ground at dusk or dawn which makes them difficult to discover. An Earth-orbiting search telescope is an efficient and cost-effective tool for discovering these objects.ASTEROIDFINDER was planned to use a body-fixed $25 \mathrm{~cm}$ wide-field telescope to continuously scan the sky in the range of $30^{\circ}$ to $60^{\circ}$ solar elongation. As in ground-based surveys, asteroids are identified through their apparent motion. The instrument was optimized for point-source detection. It used unfiltered electron-multiplied CCD sensors (EMCCD) to suppress read-out noise combined with onboard stack-register pre-processing to enable the use of a small and agile spacecraft platform. It was expected that ASTEROIDFINDER could double the number of known IEOs, increase the discovery rate at deep-interior orbits, and wouldalso discover a much larger number of Aten asteroids. From the start, the spacecraft was designed to fit pre-defined secondary payload envelopes of several launch providers (Fig. 7), and to be compatible with frequently used SunSynchronous low-Earth orbits (SSO). [88][89][90] However, the design was flexible enough to be enlarged, simplified and adapted to a later envisaged dedicated launch on a FALCON-1e launch vehicle. [91][92][93][94]

\section{ASTEROIDSQUADS/iSSB - More of the Same}

In an ad-hoc effort for the 2011 Planetary Defence Conference, a PHA multiple flyby/impact mission concept was studied that combines a heavy lauch vehicle test launch opportunity with a concerted practical exercise of the NEO observation and interplanetary spaceflight infrastructure. In this concept, the timing of the launch vehicle test replaces the coincidence of discovery of a genuine threat and drives the selection of a target object at relatively short notice. Also, the mission profile is restricted to operations relatively close to Earth to minimize mission duration and infrastructure requirements. This study employed a simplified derivate of the then-current ASTEROIDFINDER spacecraft design equipped with a propulsion module but still fitting the originally envisaged secondary payload envelope. (Fig. 8) Thus, up to approx. 20 small spacecraft could be launched at once, using existing launcher payload

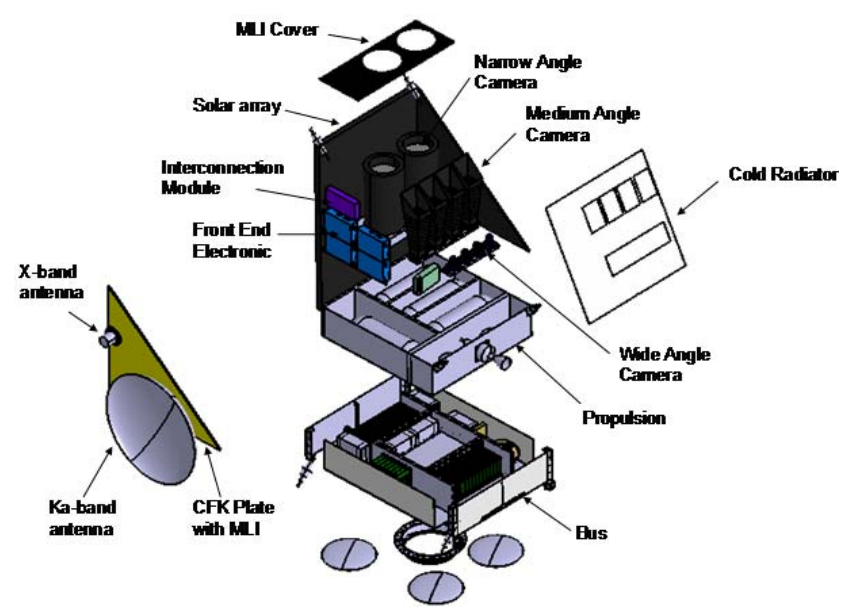

Figure 8: ASTEROIDSQUADS/iSSB kinetic impactor design based on the ASTEROIDFINDER/SSB configuration 
accommodation options (Fig. 9), to exercise deep space flotilla operations that can be expected in a real asteroid deflection case. It preserved some of the AFI features, particularly the EMCCD sensors, though in this case to achieve close-up imaging of the target NEA right down to impact at up to 1000 frames/s. [28] The comprehensive exercise of a massively parallel deflection scenario combined with cameras and other instruments using the required high-speed data link would provide planetary science and civil defence with Asteroid Serendipitous Quantitative Understanding and Assessment of Deflection Strategies, based on an improved interplanetary flight capable Standardized Satellite Bus kit which provides a wide choice of functional units from pastand present projects and studies that serves as a point of departure configuration for the next step.
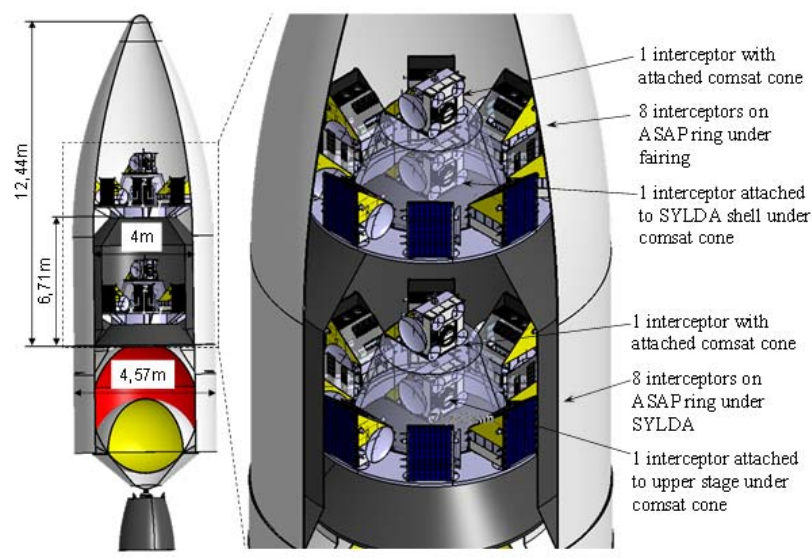

Figure 9: ASTEROIDSQUADS/iSSB launch configuration with 20 impactors, all mass shown here except for the launch vehicle's fairing is carried to kinetic impact [28]

With the ASTEROIDSQUADS/iSSB impactor design and the GOSSAMER Roadmap SPO mission concept and its separable instrument orbiter, [80] a mission concept (Fig.10) emerges for a sail-based active hypervelocity kinetic impact on a retrograde orbit, putting within reach encounter velocities in excess of $75 \mathrm{~km} / \mathrm{s}$ for kinetic impactors larger than $100 \mathrm{~kg}$. [120][121][122] Terminal guidance at such closing speeds is a formidable challenge, [82] but possible $[123][124][125]$ and enhanceable to cooperative NEA targets by pre-landed transponders. [78][83][111]

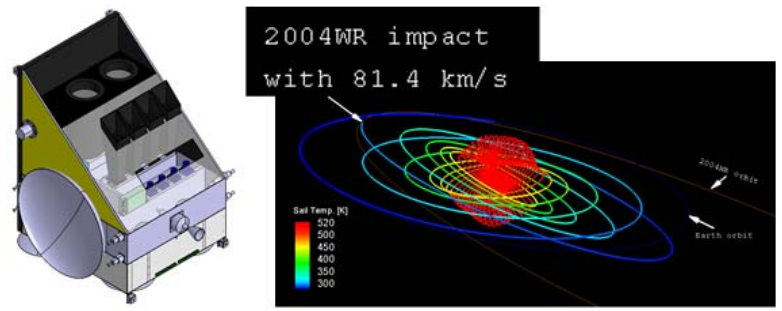

Figure 10: ASTEROIDSQUADS/iSSB imaging kinetic impactor [28] and head-on retrograde solar sail intercept trajectory, sail temperature colour-coded [122]

\section{GetTing There}

Recent interplanetary missions have brought developments that favour small spacecraft. But small spacecraft also pose their own unique challenges, some resulting from the opportunities that uniquely present themselves to them, others from the common misunderstanding that size matters in terms of the effort required or total cost of ownership.

\section{A little Far Out - Launch to Earth Escape Capabilities}

Many launch vehicles have a minimum payload weight that is due to the advances in spacecraft miniaturization no longer filled by smaller interplanetary missions. For example, IKAROS was added as ballast to achieve minimum lauch mass of the H-IIA launch vehicle of the Japanese Venus probe AKATSUKI, and therefore not massoptimized. [42] Additionally, one interplanetary and three Earth-orbiting cubesats were carried. The launch of HAYABUSA-2 followed this template by carrying three additional payloads: the $59 \mathrm{~kg}$ Proximate Object Close flyby with Optical Navigation (PROCYON), the $2.85 \mathrm{~kg}$ SHIN'EN 2 student-built interplanetary communication experiment, and ARTSAT2: DESPATCH (FO-81), also an interplanetary radio experiment [95]. Future launches may follow the same concept and have secondary passengers added that go along into parking orbit or even all the way into the final escape trajectory. This trend will likely offer affordable launch opportunities also to small interplanetary missions as those discussed above, though under similar constraints as for secondary passengers to Earth orbit.

It will pose significant time constraints, physical size constraints, and AIV challenges to these projects which will be highly unusual to the established interplanetary missions and science community, but have been mastered in the course of PHILAE and MASCOT.

\section{Here and Now - the AIV/AIT Challenges}

The Assembly, Integration and Test/Verification (AIT/AIV) is the final stage in producing a spacecraft and readying it for launch. It includes the simulation and test of the expected space environment and flight operation to verify and demonstrate the overall performance and reliability of the flight system. Choosing the right philosophy or approach of the Verification and Validation process is crucial and driven by risk tolerance. Less verification implies but does not necessarily create more risk. More verification implies but does not guarantee less risk [96]. The classical verification approach (Prototype Approach) which evolves in a mostly sequential and also successive fashion would be of course the most reliable method to choose as it gives the highest confidence that the final product performs well in all aspects of the mission [97]. However, if the schedule is heavily constrained in time, this extensive and time consuming method cannot be applied. On the other hand, the Protoflight Approach, where a single flight model is tested with replacing critical subsystems during the integration process, is also not applicable, since it 


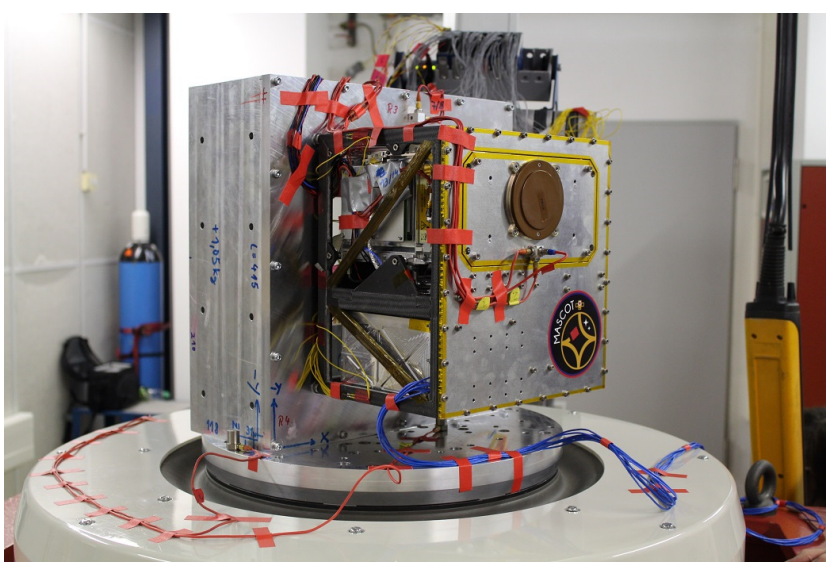

Figure 11: The MASCOT Structure Thermal Model 2.1 on the test stand during vibration tests at DLR Bremen

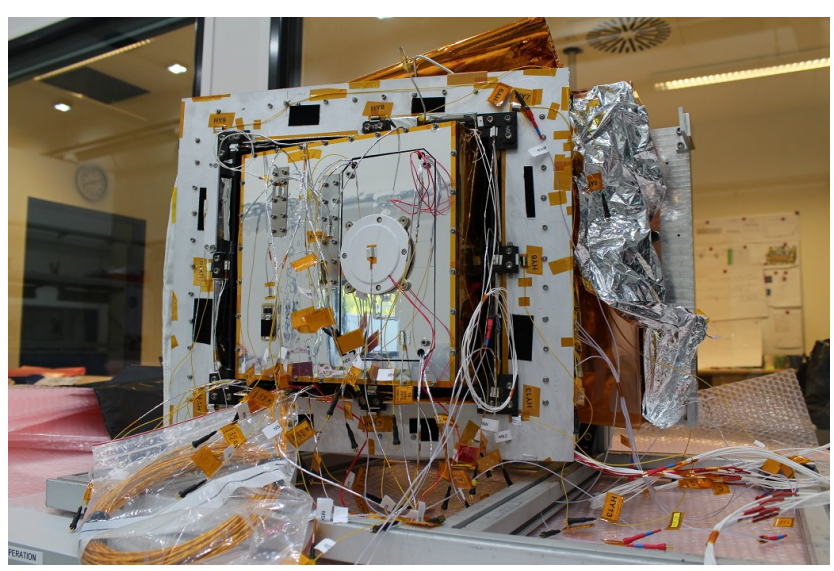

Figure 12: The MASCOT Structure Thermal Model 2.2 in preparation for Thermal Vacuum Test in Bremen

is very likely that the chosen payloads and the system itself have very heterogeneous maturity levels. Hence, the test philosophy will lead to a Hybrid Approach with a mixture of conventional and tailored model strategies. This approach is common practice in scientific robotic missions [96] but it can be maximized for effectivity and time even further. The project can start with a baseline on the classical sequential approach to ensure a minimum number of physical models required to achieve confidence in the product verification with the shortest planning and a suitable weighing of costs and risks. But this approach can be adapted on a case by case scenario, where the model philosophy evolves along the verification and test process depending on the particular system and subsystem readiness. This includes test models reorganization, refurbishing and re-assigning previous models for other verification tasks if appropriate, skipping test cases, parallel testing of similar or equal models and for some components allowing the qualification on system level. More specifically, parallelization of testing activities using identical copies and flexibility in the model philosophy will create independent unique test threads only joining their dependencies at key points where other optional roads could be chosen. Like Concurrent

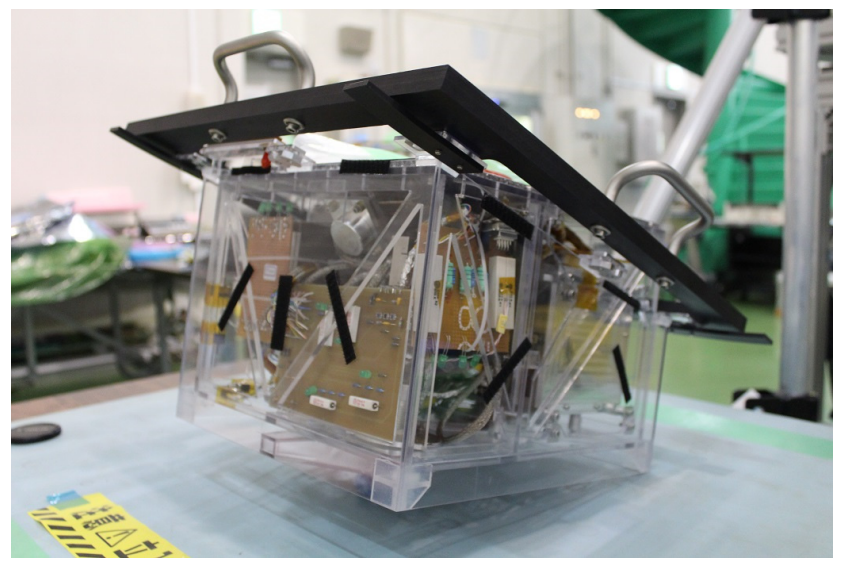

Figure 13: The MASCOT Engineering Model (EM) awaiting the Initial Integration Test at ISAS

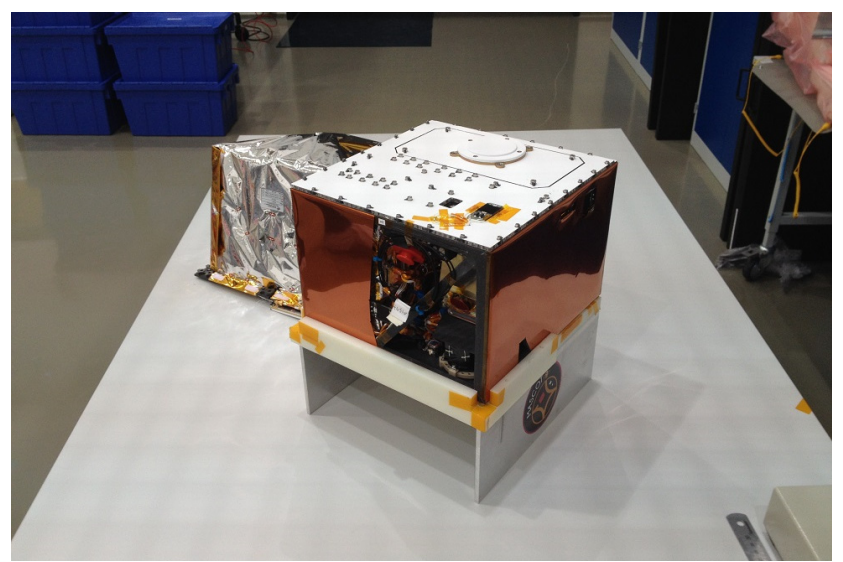

Figure 14: The MASCOT Engineering Qualification Model (EQM) ready for the Advanced Engineering Test

Engineering, a methodology based on the parallelization of engineering tasks nowadays used for optimizing and shorten design cycles in early project phases, the term "Concurrent AIV" has recently been introduced to express many simultaneous running test and verification activities [98].

In effect, the development, test and verification track of Software Development, Functional Testing, Mechanical AIV and Thermal AIV can get their own independent routes sharing their verification processes. Almost all environmental and functional tests with subsystems can be performed on EM and STM level before the QM and FM are fully assembled which effectively reduced potential delays. Seven models of MASCOT used in parallel are shown in Figs. 11 to 17. In addition, the development of the onboard software including individual instrument and subsystem software, can be performed completely independent with first simulated payloads and later with real hardware-in-the-loop electronic when they become available. This way, every payload and subsystem can freely do debugging tests which can take longer time independently. With this approach, most of the problems for 
the interfaces and functionality of each subsystem can be found before flight model integration.

The challenges in creating parallel development lines will be found in team and facility resources if these are not readily and on-demand available. The key is to identify test dependencies, test sequences and which test could be performed in parallel. In addition, this philosophy is also more complex as it requires the overview of the development process of the mother spacecraft, the ongoing progress on system level as well as the insight in all payloads and subsystems.

It may sound unreasonable to perform the development of a spacecraft in such a manner, whereas well established methods form a 'standard way'. But if a certain project is left with no choice of having the luxury of excessive testing, such an approach may be the only option. That this method is not just a theory can be seen in the DLR MASCOT project - a fast paced and high performance deep space project. It applied a unique mix of conventional and tailored model philosophies and it was possible to dynamically adapt the test program, limited by a fixed launch date, to accomplish for the shortest planning and a suitable weighing of costs and risks. A dynamically adapted test programme using Concurrent Assembly Integration and Verification (AIV) kept project risk within acceptable bounds and shortened the system-level AIV phase from the typical 4 to 5 year to $2 \frac{1}{2}$ years within a project timeline of 3 years focused on the specific launch opprotunity. When the definite launch opportunity was confirmed, MASCOT already was in the position to benefit from a preceding phase of a range of lander concept studies at the DLR Bremen Concurrent Engineering Facility since 2008. (It is this situation that is not unlike that of an Earth-orbital small spacecraft awaiting manifestation for a shared launch with another, larger main payload, as described earlier.)

Within this $2 \frac{1}{2}$-year AIV phase, from the start with the first breadboard model, the MASCOT team has successfully completed approx. 30 MASCOT system level tests, including Shock and Vibration, Thermal Vacuum, Full

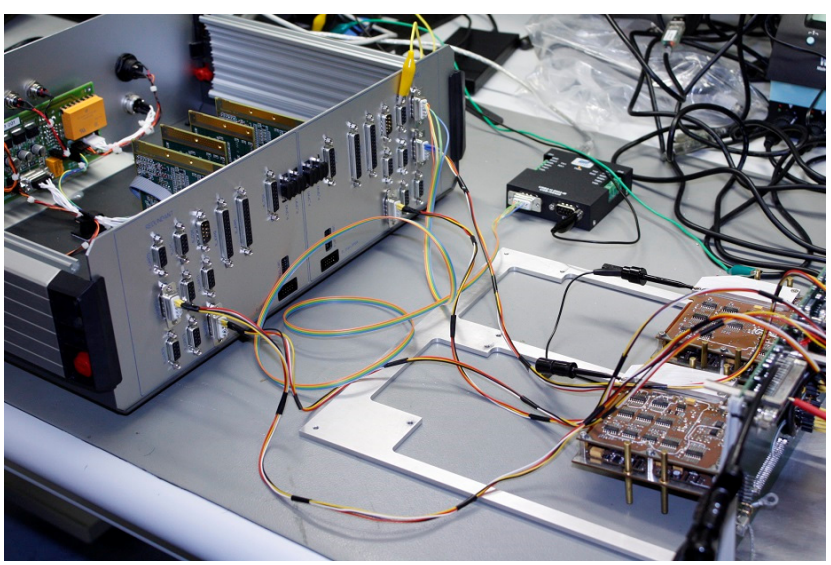

Figure 15: The MASCOT Software Development and Validation Facility (SDVF) in operation
System Functional, EMC and Integration campaigns. On its carrier satellite HAYABUSA-2 it has fulfilled additionally approx. 10 test campaigns for Sinusoidal Vibration and Mass Balance, Acoustic Vibration, Thermal Vacuum and System End-to-End tests. To develop the MASCOT system and to make it flight ready, more than 50 additional System Unit tests were performed, excluding any test performed by the Payloads or other subsystems provided by the collaborating partners during subunit development. This culminates in amost 100 different test campaigns performed in roughly half the time usually allocated for such a prototype project which would follow a standardized way.

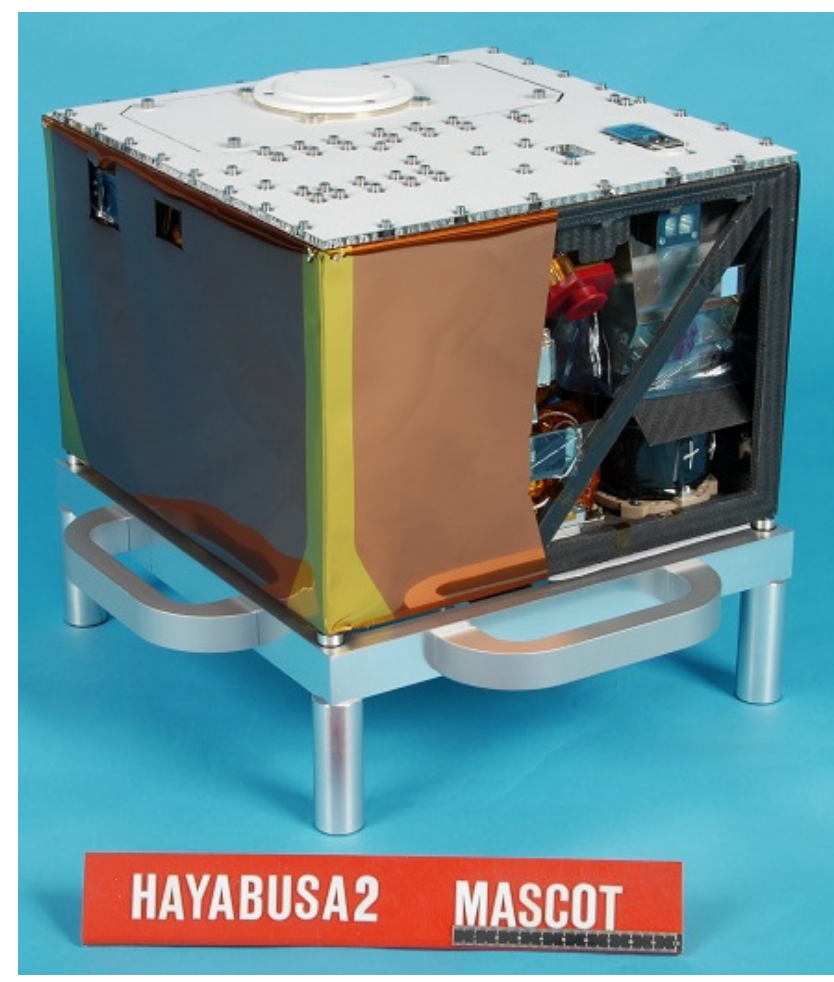

Figure 16: The MASCOT Flight Model (FM) ready to go

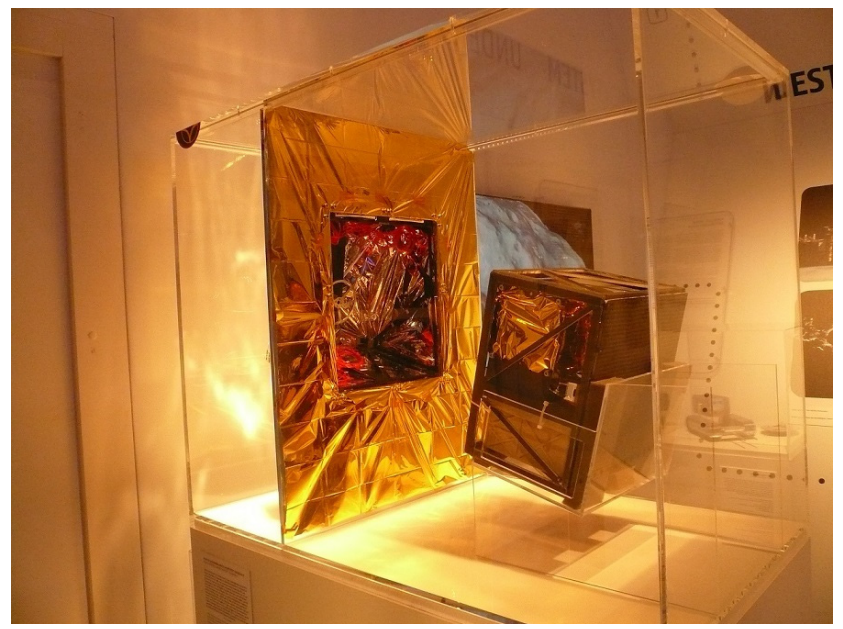

Figure 17: The MASCOT Structure Thermal Model 1 on public relations assignment at the ILA, Berlin 
Currently, the fully integrated MASCOT Flight Spare (FS) is used as a precision reference model in addition to the mainly functional Ground Reference Model. They continue in functional and environmental testing on system level, with the SDVF (Fig. 15) for software and operations development. If required, these could be joined by more still to be (re-)built partial hardware models. Also, some subsystem test campaigns necessary for optimized operations planning are ongoing or are being planned. With the fully integrated FS, engineering aspects can be covered during science calibration campaigns and vice versa. All these activities expand the experience base for future MASCOT activities leading up to the asteroid surface science mission. [58][99][101]

\section{DOING THINGS}

Planetary defence is still a new and developing field. [9] Related instruments to be carried on spacecraft as those discussed above can also extend in their operating and design principles beyond those commonly carried on science missions. It is, as in AIDA or DEEP IMPACT, possible to conduct impact impulse transfer studies (i.e., employ a "very fast lander") for the promising deflection concept of kinetic impactors. A ranging beacon for extended precision orbit determination by Earth-based facilities can be deployed, also in a MASCOT-like solar-powered lander dropped by solar sail or other low-thrust propelled main spacecraft which can not be used as easily as a ballistic orbiter to do precision orbit determination ranging of an asteroid but can reach targets inaccessible to conventionally fuelled propulsion missions.

\section{CONCLUSION}

In this paper we present an overview of the characteristics of small spacecraft missions, from Earth orbit and interplanetary mission experience in DLR. Our experience has shown that the transition to small mission environments demands a considerable change of culture, customs and habits in spacecraft design work from those used to working on 'large' scentific interplanetary missions. [100][101] It also shows that with focused work, determination, and an open mind, this challenge can be mastered - and enjoyed.

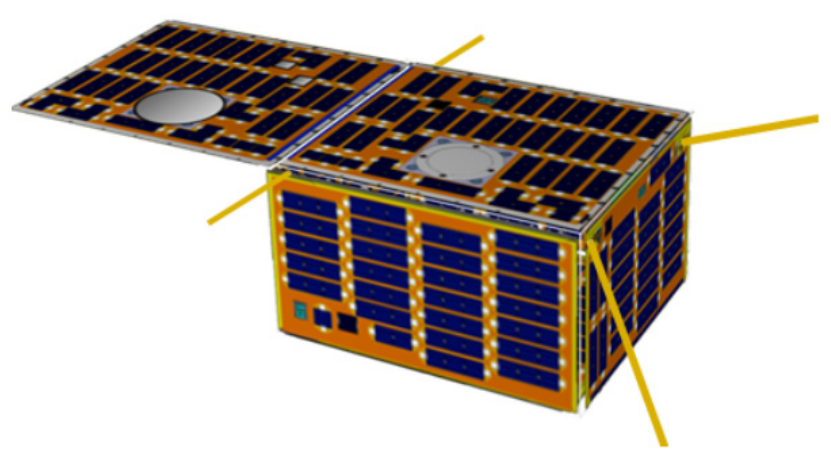

Figure 18: MASCOT2 lander design for AIM mission

\section{REFERENCES}

[1] A. Zimmer, E. Messerschmid, Target Selection and Mission Analysis of Human Exploration Missions to Near-Earth Asteroids, Planetary Defence Conference 2011, IAA-WPP-323, S05_0930_2150884.

[2] O.P. Popova, P. Jenniskens, V. Emel'yanenko, et al. Chelyabinsk Airburst, Damage Assessment, Meteorite Recovery and Characterization.Science 342 (2013).

[3] Число пострадавших при падении метеорита приблизилось к 1500, РосБизнесКонсалтинг (RBC), 18 February 2013, 00:00, http://top.rbc.ru/incidents/18 /02/2013/845595.shtml (accessed 22JAN2015 14:05)

[4] Andrew E. Kramer, After Assault From the Heavens, Russians Search for Clues and Count Blessings, New York Times, 17 February 2013, http://www.nytimes.com/2013/02/17/world/europe/russiar u-seek-clues-and-count-blessings-after-meteor-

blast.html?_r=0 , also: Benjamin Bidder, MeteoritenHagel in Russland: "Ein Knall, Splittern von Glas", http://www.spiegel.de/wissenschaft/weltall/meteoritenhagel-in-russland-a-883565.html (accessed 22JAN2015)

[5] Meteorite hits Russian Urals: Fireball explosion wreaks havoc, up to 1,200 injured (photos, videos), February 16, 2013, 23:58, http://rt.com/news/meteorite-crash-uralschelyabinsk-283/ (accessed 22JAN2015)

[6] Meteorite-caused emergency situation regime over in Chelyabinsk region, Russia Beyond The Headlines (Rossiyskaya Gazeta), Interfax, 5 March 2013, http://rbth.co.uk/news/2013/03/05/meteoritecaused_emergency_situation_regime_over_in_chelyabins k_region_23513.html (accessed 22JĀN2015)

[7] S. Buhl, K. Wimmer, S. Pethukhov, P. Murmorov, et al, Trajectory Projection of the Chelyabinsk Superbolide and Location of Recorded Meteorite Finds, status of 18 July 2013, www.meteorite-recon.com via http://en.wikipedia. org/wiki/Chelyabinsk_meteor\#mediaviewer/File:Strewnfi eld_map_of_Chelyabinsk_meteorites.jpg (22JAN2015)

[8] M. Boslough, D. Crawford, D. Spalding, N. Singer, R. Montoya, Sandia supercomputers offer new explanation of Tunguska disaster - Smaller asteroids may pose greater danger than previously believed, December 17, 2007, https://share.sandia.gov/news/resources/releases/2007/aste aste.html (accessed 24OCT2015).

[9] $4^{\text {th }}$ IAA Planetary Defense Conference 2015 (PDC15) Conference abstracts, papers and presentations Conference report, http://pdc.iaaweb.org/?q=content/2015-frascati (accessed 210CT2016) 
[10] L.W. Alvarez, W. Alvarez, F. Asaro, H.V. Michel, Extraterrestrial cause for the Cretaceous-Tertiary extinction". Science 208 (4448): 1095-1108.

[11] D.A. Kring, Guidebook to the Geology of Barringer Meteorite Crater, Arizona (a.k.a. Meteor Crater), 2007, Lunar and Planetary Institute, LPI Contribution No. 1355, http://www.lpi.usra.edu/publications/books/barringer_crat er_guidebook/ (accessed 24OCT2015).

[12] University of Bologna (Italy) - Department of Physics Tunguska Home Page - Tunguska Scientific Publications, 2010, http://www-th.bo.infn.it/tunguska/tu99public.htm (accessed 24OCT2015).

[13] J.S. Lewis, Rain of Iron and Ice: The Very Real Threat Of Comet And Asteroid Bombardment, 1997 amended paperback edition.

[14] A.B. Chamberlin, NEO Discovery Statistics, http://neo.jpl.nasa.gov/stats/ (accessed 21OCT2014)

[15] A. Harris (U.S.), The Value of Enhanced NEO Surveys, IAA-PDC13-05-09

[16] A. Harris (U.S.), The Population of Near-Earth Asteroids and Current Survey Completion, IAA-PDC13-02-09P

[17] P. G. Brown, J. D. Assink, L. Astiz, et al., A 500-kiloton airburst over Chelyabinsk and an enhanced hazard from small impactors, Nature 503 (2013), 238-241.

[18] P. Brown, et al., The flux of small near-Earth objects colliding with the Earth, Nature 420 (2002), 294-296.

[19] M.B.E. Boslough, D.A. Crawford, Low-altitude airbursts and the impact threat, International Journal of Impact Engineering 35 (2008) 1441-1448

[20] M. Boslough, Airburst Warning and Response, Planetary Defence Conf. 2011, IAA-WPP-323, S4_1610_2166721

[21] G. Gisler, Low-Altitude Atmospheric and Water-Surface Effects of Small Impacts, IAA-PDC13-05-05

[22] Linda Billings, NASA/JPL Near-Earth Object Program Office, Newly Released Map Data Shows Frequency of Small Asteroid Impacts, Provides Clues on Larger Asteroid Population, Nov. 14, 2014, http://neo. jpl.nasa.gov/news/news186.html (accessed 22JAN2015)

[23] J.T. Grundmann, Small Solar System Body Mitigation: A Realist's Approach, IAA-WPP-301, P206 (therein only appendix included, full paper on request)

[24] L.A. Kleiman, Project Icarus: an MIT Student Project in Systems Engineering, Cambridge, Massachusetts, MIT Press, 1968, and MIT Report No. 13.
[25] R. Kahle, Modelle und Methoden zur Abwendung von Kollisionen von Asteroiden und Kometen mit der Erde, D 83, TU Berlin, August 2005.

[26] J. Bellerose, C. Foster, D. Morrison, et al., Performance and Derived Requirements of a Gravity Tractor serving as a precursor to a Kinetic Impactor within the NEOShield Study Framework, IAA-PDC13-04-18.

[27] A. Gibbings, M. Vasile, J.-M. Hopkins, et al, Experimental Characterization of the Thrust Induced by Laser Ablation onto an Asteroid, IAA-PDC13-04-21.

[28] J.T. Grundmann, S. Mottola, M. Drentschew, M. Drobczyk, et al., ASTEROIDSQUADS/iSSB - a Synergetic NEO Deflection Campaign and Mitigation Effects Test Mission Scenario, IAA-WPP-323 S5_0910_2162714.

[29] M. Boslough, Impact Decision Support Diagrams, Planetary Def. Conf. 2011, IAA-WPP-323, P68_2167459

[30] ESTEC/ESA, Margin philosophy for science assessment studies, SRE-PA/2011.097/ iss. 1/ rev. 3, 15/06/2012.

[31] M.D. Rayman, P.A. Chadbourne, et al., Mission Design for Deep Space 1: a Low-Thrust Technology Validation Mission, Acta astronautica 45 (4-9): 381-388 (1999)

[32] M.D. Rayman, P. Varghese, D.H. Lehman, L.L. Livesay, Results from the Deep Space 1 technology validation mission, Acta Astronautica 47 (2-9): 475-487 (2000)

[33] M.D. Rayman, The successful conclusion of the Deep Space 1 Mission: important results without a flashy title, Space Technology 23 (2): 185-196 (2003).

[34] D.M. Di Cara, D. Estublier, Smart-1: An analysis of flight data, Acta Astronautica 57 (2-8): 250-256 (2005).

[35] H. Yano, T. Kubota, H. Miyamoto, T. Okada, et al., Touchdown of the Hayabusa Spacecraft at the Muses Sea on Itokawa, Science Vol. 312 (2006), 1350-1353.

[36] J. Kawaguchi, A. Fujiwara, T. Uesugi, Hayabusa - Its technology and science accomplishment summary and Hayabusa-2, Acta Astronautica, Vol. 62, 639-647, 2008.

[37] http://isa.ifsi-roma.inaf.it/BepiColombo/BC1/BC1.html (accessed 210CT2014)

[38] J. Kawaguchi, O. Mori, Y. Shirasawa, M. Yoshikawa, On the Trojan asteroid sample and return mission via solar-power sail - an innovative engineering demonstration, ACM2014.

[39] O. Mori, H. Sawada, R. Funase, et al., Development of First Solar Power Sail Demonstrator - IKAROS.

[40] H. Yano, O. Mori, S. Matsuura, et al., IKAROS Team, JAXA Solar Power Sail Working Group, The Solar Power Sail Mission to Jupiter Trojans, $10^{\text {th }}$ IAA LCPM 2013, S5 
[41] O. Mori, Y. Shirasawa, H. Sawada, Y. Mimasu, et al., IKAROS Extended Mission and Advanced Solar Power Sail Mission, $63^{\text {rd }}$ IAC 2012, IAC-12,D1,1,3,x15786.

[42] Masahiro Umesato, Takakazu Okahashi, Sailing Into Space - Two Men in a Race Against Time, http://www.nec.com/en/global/ad/cosmos/ikaros/.

[43] A. Harris (DLR), the NEOShield Consortium, NEOShield - Progress Towards an International NEO Mitigation Program, IAA-PDC13-01-06.

[44] G. Schwehm, ROSETTA - The comet rendezvous mission, ESA-SP-1179

[45] K.-H. Glassmeier, et al., The Rosetta Mission: Flying Towards the Origin of the Solar System, Space Science Reviews (2006), DOI: 10.1007/s11214-006-9140-8

[46] S. Ulamec et al., RoLand, a Lander System for an active comet, IAA-95-IAA.11.1.06 (1995).

[47] S. Ulamec, J. Biele, J.T. Grundmann, J. Hendrikse, C. Krause, Relevance of PHILAE and MASCOT in-situ Investigations for Planetary Defense, IAA-PDC15-04-08.

[48] J. Biele, R. Willnecker, J.-P. Bibring, et al., Philae (Rosetta Lander): Experiment status after commissioning, Advances in Space Research 38 (2006) 2025-2030.

[49] M. Thiel, J. Stöcker, C. Robe, N.I. Kömle, G. Kargl, et al., The Rosetta Lander Anchoring System, 2003.

[50] M. Hilchenbach, Simulation of the Landing of Rosetta Philae on Comet 67P/Churyumov-Gerasimenko, SIMPACK User Meeting, 2004, p. 25.

[51] J. Biele, S. Ulamec, et al., The landing(s) of Philae and inferences about comet surface mechanical properties, Science, Vol.349, issue 6247, aaa9816-1 (2015).

[52] E. Hand, Comet lander's scientific harvest may be its last - Philae has fallen silent after fragmentary messages, Science, Vol.349, issue 6247, 459-460 (2015); also cf. M. Braun, K. Geurts, S. Ulamec, New command for Philae, http://www.dlr.de/dlr/en/desktopdefault.aspx/tabid10081/151_read-16365/\#/gallery/21643

[53] JAXA press release, Name Selection of Asteroid 1999 JU3 Target of the Asteroid Explorer "Hayabusa2", http://global.jaxa.jp/press/2015/10/20151005_ryugu.html, also http://www.minorplanetcenter.net/iau/lists/Numbered MPs160001.html ， http://scully.cfa.harvard.edu/cgibin/showcitation.cgi?num=162173 (09OCT2015)

[54] T.-M. Ho, et al., MASCOT - The Mobile Asteroid Surface Scout onboard the HAYABUSA2 Mission, 2016, SSR, DOI 10.1007/s11214-016-0251-6.
[55] C. Ziach, et al., MASCOT, the Small Mobile Asteroid Landing Package on its Piggyback Journey to $1999 \mathrm{JU}_{3}$ : Pre-Launch and Post-Launch Activities, IAC-15-A3.4.6

[56] C. Lange, R. Findlay, C. Grimm, et al., "How to build a $10 \mathrm{~kg}$ autonomous Asteroid landing package with $3 \mathrm{~kg}$ of instruments in 6 years?" - Systems Engineering challenges of a high-density deep space system in the DLR MASCOT project, 2624640 (1325), SECESA 2012.

[57] R. Findlay, T.-M. Ho, C. Lange, et al., A Small Asteroid Lander Mission to Accompany HAYABUSA-II, Proceedings of the 63rd International Aeronautical Congress, Naples, Italy, 2012, IAC-12-A3.4.7.

[58] J.T. Grundmann, V. Baturkin, et al., "You've got 2 Years, 6 Months, 1 Week and 48 Hours!" - the Ongoing Engineering Adventure of MASCOT and its Implications for Planetary Defence Missions, IAA-PDC13-04-06P.

[59] C. Ziach, T.-M. Ho, C. Grimm, R. Findlay, C. Lange, et al., The Final Stages of MASCOT, a Small Asteroid Lander to Accompany HAYABUSA-II, IAC-13-A.3.4.6.

[60] M. Lange, O. Mierheim, C. Hühne. MASCOT Structures Design and Qualification of an "Organic" Mobile Lander Platform for Low Gravity Bodies. Proc. of '13th European Conference on Space Structures, Materials \& Environmental Testing', Braunschweig, Germany, ESA SP-727 (June 2014)

[61] M. Lange, et al. MASCOT - A Lightweight MultiPurpose Lander Platform. Proc. of $12^{\text {th }}$ European Conf. on Space Structures, Materials \& Environmental Testing, Noordwijk, ESA SP-691 (July 2012)

[62] E. Canalias, M. Deleuze, et al., Analysis of the Descent and Bouncing Trajectory of MASCOT on 1999JU3, IPPW2015-6105, International Planetary Probe Workshop, 2015, Cologne

[63] L. Celotti, et al., MASCOT thermal subsystem design challenges and solution for contrasting requirements, $45^{\text {th }}$ Intern'l Conf. on Environmental Systems, ICES-2015-83

[64] J.T. Grundmann, J. Biele, R. Findlay, S. Fredon, et al., One Shot to an Asteroid - MASCOT and the Design of an Exclusively Primary Battery Powered Small Spacecraft in Hardware Design Examples and Operational Considerations, № 3051, Europ. Space Power Conf. 2014.

[65] C. Grimm, et al., DLR MASCOT on HAYABUSA-II, A Mission That May Change Your Idea of Life! - AIV Challenges in a Fast Paced and High Performance Deep Space Project, sr104H00604H, ISTS 2013.

[66] C. Krause, T.-M. Ho, S. Ulamec, T. Zoest, A. Herique, J. Biele, et al., MAGIC - Mobile Autonomous Generic Insstrument Carrier for the in-situ Investigation of NEO Surfaces and Interior, IAA-WPP-323, P51_2161981. 
[67] C. Lange, Using MBSE Methods to Design Generic System Platforms and Derivatives: A Methodology Applied to the Mobile Asteroid Surface Scout, Systems Engineering and Concurrent Engineering for Space Applications, SECESA, 2014, Stuttgart, Germany.

[68] H. Schumann, A. Braukhane, et al., Overview of the New Concurrent Engineering Facility at DLR, SECESA 2008.

[69] R. Findlay, A. Braukhane, et al., Implementation of Concurrent Engineering to Phase B Space System Design, DLRK 2011 \& CEAS Space Journal 2011.

[70] R. Findlay, P. Spietz, J.F. Pedersen, S. Gerené, Concurrent engineering through the stages: AsteroidFinder (Phase B), SECESA 2010, 2072559.

[71] J. Kepler, De Cometis Libelli Tres, 1619.

[72] J.C. Maxwell, A Treatise on Electricity and Magnetism ( $1^{\text {st }}$ ed.), 2, 391, Oxford, 1873.

[73] A. Bartoli, Sopra I movementi prodotti della luce et dal calorie, Florence, Le Monnier, 1876; also Nuovo Cimento, 15, 193, 1884.

[74] P. Lebedev, Untersuchungen über die Druckkräfte des Lichtes, Annalen der Physik, 1901

[75] E.F. Nichols, G.F. Hull, The Pressure due to Radiation, Phys. Rev. (Series I) 17, 91-104, 1903

[76] W. Seboldt, M. Leipold, et al,. Ground-based demonstration of solar sail technology. Rio de Janeiro, 2000. $51^{\text {st }}$ Intern'l Astronautical Congress. IAF-00-S.6.11.

[77] U. Geppert, B. Biering, F. Lura, J. Block, M. Straubel, R. Reinhard, The 3-Step DLR-ESA GoSSAMER road to solar sailing, Adv.in Space Res. 48 (2011) 1695-1701.

[78] B. Dachwald, H. Boehnhardt, U. Broj, U.R.M.E. Geppert, et al., GossAmER Roadmap Technology Reference Study for a Multiple NEO Rendezvous Mission, in: M. Macdonald (ed.), Adv. in Solar Sailing, 2014 ( $3^{\text {rd }}$ International Symposium on Solar Sailing)

[79] C.R. McInnes, V. Bothmer, et al, Gossamer Roadmap Technology Reference Study for a Sub- $\mathrm{L}_{1}$ Space Weather Mission, in: M. Macdonald (ed.), Adv. in Solar Sailing, 2014 ( $3^{\text {rd }}$ International Symposium on Solar Sailing)

[80] M. Macdonald, C. McGrath, et al., GossAMER Roadmap Technology Reference Study for a Solar Polar Mission, in: M. Macdonald (ed.), Adv. in Solar Sailing, 2014 (3 $3^{\text {rd }}$ International Symposium on Solar Sailing)

[81] P. Seefeldt, W. Bauer, B. Dachwald, J.T. Grundmann, M. Straubel, M. Sznajder, N. Toth, M.E. Zander, Large Lightweight Deployable Structures for Planetary Defence: Solar Sail Propulsion, Solar Concentrator Payloads, Large-scale Photovoltaic Power, IAA-PDC15-P-20.
[82] J.T. Grundmann, et al., Spacecraft for Hypervelocity Impact Research - an Overview of Capabilities, Constraints, and the Challenges of getting there, $13^{\text {th }}$ Hypervelocity Impact Symposium 2015, session 11, \#20.

[83] J.T. Grundmann, W. Bauer, J. Biele, F. Cordero, B. Dachwald, D. Herčík, A.D. Koch, A. Koncz, C. Krause, T. Mikschl, S. Montenegro, D. Quantius, M. Ruffer, K. Sasaki, N. Schmitz, W. Seboldt, P. Seefeldt, M. Sznajder, N. Tóth, E. Wejmo, From Sail to Soil - Getting Sailcraft Out of the Harbour on a Visit to One of Earth's Nearest Neighbours, IAA-PDC15-04-17.

[84] http://esamultimedia.esa.int/docs/gsp/completed/AIDA _MissionRationale_InterimRelease.pdf, ://esamultimedia .esa.int/docs/gsp/AIDAProjectOptions_vla.pdf

[85] W. Kofman, et al., Properties of the 67P/ChuryumovGerasimenko interior revealed by CONSERT radar, Science, Vol.349, issue 6247, aab0639-1 (2015).

[86] AIM's asteroid lander, http://www.esa.int/spaceinimages /Images/2015/04/AIM_s_asteroid_lander , http://www. esa.int/Our_Activities/Space_Engineering_Technology/A steroid Impact Mission (accessed 24OCT2015).

[87] C. Lange, J.T. Grundmann, J. Hendrikse, M. Lange, N. Tóth, Technology and knowledge reuse concepts to enable responsive NEO characterization missions based on the MASCOT lander, IAA-PDC15-P-65.

[88] S. Mottola, et al., AsteroidFinder: Unveiling the Population of Inner Earth Objects, 2008, IAC-08-A3.5.6

[89] S. Mottola, J. Behrens, A. Börner, S. Gerene, et al., AsteroidFinder/SSB: A German Mission for the Search of IEOs, 2009, IAA-WPP-301, 01_10.

[90] J.T. Grundmann, R. Axmann, V. Baturkin, et al., Small satellites for big science: the challenges of high-density design in the DLR Kompaktsatellit ASTEROIDFINDER/SSB, COSPAR 2010, B-04-0043-10.

[91] R. Findlay, O. Eßmann, J.T. Grundmann, H. Hoffmann, E. Kührt, et al., A Space-Based Mission to Characterize the IEO Population, 2011, IAA-WPP-323, P02_2149803.

[92] J.F. Pedersen, et al., AsteroidFinder: A Small Satellite to Characterize the IEO Population, SSC11-IV-3.

[93] J.F. Pedersen, R. Findlay, H. Müller, O. Eßmann, DLRKompaktsatellit: A Small German Spacecraft Developed by DLR for Substantial Scientific Return, DLRK 2011.

[94] R. Findlay, et al., AsteroidFinder: Implementing a Small Satellite Mission to Detect IEOs, IAC-11-B4.2.8 
[95] wikipedia: 2014 in spaceflight, http://en.wikipedia.org/ wiki/2014 in spaceflight, http://en.wikipedia.org/wiki/ PROCYON , http://www.pe0sat.vgnet.nl/satellite/ commercial-scientific/shinen-2/, http://www.pe0sat.vgnet .nl/satellite/commercial-scientific/artsat2/ (12JAN2015).

[96] Larson, J.W., et al.: Applied Space Systems Engineering, Space Tech. Series, McGraw-Hill Companies, Inc., 2009.

[97] Ley, W., Wittmann, K., Hallmann, W.: Handbook of Space Technology, John Wiley \& Sons, Ltd., 2009.

[98] Grimm, C., et al.: Concurrent AIV and Dynamic Model Strategy in Response to the New Normal of so called Death March Projects, Aerospace Testing Seminar 2014.

[99] C.D. Grimm, J.T. Grundmann, J. Hendrikse, On Time, On Target - How the Small Asteroid Lander MASCOT Caught a Ride Aboard HAYABUSA-2 in 3 Years, 1 Week and 48 Hours, IAA-PDC15-P-66.

[100] J.T. Grundmann, J. Biele, et al., The Ends of Small Practical Engineering Constraints in the Design of Planetary Defence Missions, IAA-PDC13-04-05P.

[101] C.D. Grimm, J.T. Grundmann, J. Hendrikse, et al., Going Beyond the Possible, Going Beyond the "Standard" of Spacecraft Integration and Testing! - A Summary of the DLR Mascot AIV Activities within the Hayabusa2 Project from the First Unit Hardware Test to Final Check-out before Launch -, 30 $0^{\text {th }}$ ISTS 2015.

[102] F. Mellor, Colliding Worlds: Asteroid Research and the Legitimization of War in Space, Social Studies of Science 37/4 (August 2007), pp. 499-531.

[103] C. Sagan, S.J. Ostro, Dangers of asteroid deflection, Nature 368, 501 (07 April 1994); doi:10.1038/368501a0

[104] Legal Perspectives on Space Resources and Off-Earth Mining, Session E7.2, $59^{\text {th }}$ IISL Colloquium on the Law of Outer Space, IAC 2016, Guadalajara, Mexico, http://iac2016.org/pdf/IAC2016_FP_FULL.pdf (accessed 210CT2016), p. 173

[105] AsteroidScience Intersections with In-Space Mine Engineering, ASIME 2016, Neimënster, Luxembourg, 2122 September 2016, http://europlanetscinet.fi/index.php?id=asime16 (21OCT2016)

[106] D.M. Tobin, G.S. Haag, et al., Off-The-Shelf MicroSatellites for Science and Technology Missions, $11^{\text {th }}$ AIA/USU Conference on Small Satellites, SSC97-V-4

[107] A.F. Cheng, J. Atchison, B. Kantsiper, A.S. Rivkin, A. Stickle, et al, Asteroid impact \& deflection Assessment mission, Acta Astronautica, Vol. 115, pp. 262-269, 2015

[108] J. Biele, S. Ulamec, Capabilities of Philae, the Rosetta Lander, Space Science Rev., 138, pp. 275-289; 2008
[109] S. Ulamec, J, Biele, C. Fantinati, J.-F. Fronton, et al., Rosetta Lander - after seven years of cruise, prepared for hibernation, Acta Astron., Vol. 81, pp. 151-159, 2012

[110] S. Ulamec, C. Fantinati, et al., Rosetta Lander Landing and operations on comet 67P/ChuryumovGerasimenko, Acta Astron., Vol. 125, pp. 80-91, 2016

[111] A. Peloni, M. Ceriotti, B. Dachwald, Solar-Sail Trajectory Design for a Multiple Near-Earth-Asteroid Rendezvous Mission, Journal of Guidance, Control, and Dynamics, 2016, DOI: 10.2514/1.G000470

[112] J.T. Grundmann, P. Spietz, P. Seefeldt, T. Spröwitz, GOSSAMER Deployment Systems for Flexible Photovoltaics, $67^{\text {th }}$ International Astronautical Congress 2016, Guadalajara, Mexico, IAC-16-C3.3.6.

[113] P. Seefeldt T. Spröwitz, J.T. Grundmann, Verification Testing of the GosSAMER-1 Deployment Demonstrator, $67^{\text {th }}$ International Astronautical Congress 2016, Guadalajara, Mexico, IAC-16-C2.2.3.

[114] T. Spröwitz et al, Qualification Testing of the GossAMER-1 Deployment Technology, ECSSMET 2016, \#56220.

[115] P. Seefeldt, et al., Gossamer-1: Mission Concept and Technology for a Controlled Deployment of Gossamer Spacecraft, Adv. in Space Research (2016), doi: http://dx.doi.org/10.1016/j.asr.2016.09.022.

[116] F. Dannemann, M. Jetzschmann, Technology-driven Design of a Scalable Small Satellite Platform, 4S Symposium 2016.

[117] P. Seefeldt, T. Spröwitz, E. Mikulz, et al., Controlled Deployment of Gossamer Spacecraft, ISSS 2017.

[118] http://www.robex-allianz.de/en/about-robex/topic2000-system-infrastructure/

[119] http://www.dlr.de/dlr/desktopdefault.aspx/tabid10212/332_read-19403/year-all/\#/gallery/24429

[120] B. Dachwald, R. Kahle, B. Wie, Solar Sailing Kinetic Energy Impactor (KEI) Mission Design Tradeoffs for Impacting and Deflecting Asteroid 99942 Apophis, AIAA/AAS Astrodynamics Specialist Conference and Exhibit, AIAA 2006-6178.

[121] B. Dachwald, R. Kahle, B. Wie, Head-On Impact Deflection of NEAs: A Case Study for 99942 Apophis, AIAA, PDC 2007.

[122] B. Dachwald, B. Wie, Solar Sail Kinetic Energy Impactor Trajectory Optimization for an AsteroidDeflection Mission, Journal of Spacecraft and Rockets, Vol. 44, No. 4, July-August 2007, DOI: 10.2514/1.22586. 
[123] S. Bhaskaran, B. Kennedy, Closed Loop Terminal Guidance Navigation for a Kinetic Impactor Spacecraft, IAA-PDC13-04-02.

[124] J. Lyzhoft, et al., GPU-Based Optical Navigation and Terminal Guidance Simulation of a Hypervelocity Asteroid Intercept Vehicle (HAIV), IAA-PDC13-04-23.

[125] J. Gil-Fernández, et al., The Challenge of Navigating Toward and Around a Small, Irregular NEO, IAA-WPP301, 02_03.

[126] R. Jaumann, et al., The Camera of the MASCOT Asteroid Lander on Board Hayabusa2; Space Science Reviews, 2016, DOI 10.1007/s11214-016-0263-2.

[127] M. Grott, et al., The MASCOT Radiometer MARA for the Hayabusa 2 Mission, Space Science Reviews, 2016 , DOI 10.1007/s11214-016-0272-1

[128] D. Herčík, H.-U. Auster, et al. The MASCOT Magnetometer; Space Science Reviews, 2016, DOI 10.1007/s11214-016-0236-5

[129] L. Riu, J-P. Bibring, V. Hamm, et al., Calibration of MicrOmega Hayabusa-2 Flight Model - First Results, 47th LPSC 2016, \#2109.

[130] J.T. Gundmann, J. Biele, B. Dachwald, C.D. Grimm, C. Lange, S. Ulamec, C. Ziach, T. Spröwitz, M. Ruffer, P. Seefeldt, P. Spietz, N. Tóth, J. Kawaguchi, O. Mori, A. Rittweger, J-P. Bibring, A. Braukhane, R. Boden, T. Chujo, E. Dumont, S. Jahnke, M. Jetzschmann, H. Kato, H. Krüger, M. Lange, A. Martelo Gomez, D. Massonett, Y. Mimasu, T. Okada, M. Sagliano, K. Sasaki, S. Schröder, M. Sippel, T. Skoczylas, E. Wejmo, Small Landers and Separable Sub-Spacecraft for Near-term Solar Sails, $4^{\text {th }}$ International Symposium on Solar Sailing, 2017, Kyoto, Japan.

[131] T. Spear, et al., NASA FBC Task Final Report \& NASA FBC Task Final Report Briefing 1-5, Briefing Presentations, http://mars.nasa.gov/msp98/misc/fbctask .pdf , ftp://ftp.hq.nasa.gov/pub/pao/reports/2000/ fbcbriefingpkg1.pdf to ..5.pdf (accessed 09JAN2016), cf. $\# 1$, slide $8,4^{\text {th }}$ bullet; $\# 3$, slide 5 ; $\# 3$, slide $8,1^{\text {st }}$ bullet.

* I. Anderson, M. Barre, D. Pegg, P.-J. Vetesse, Apogee, in: Under Wraps, Chrysalis, 1984

\section{BIOGRAPHY}

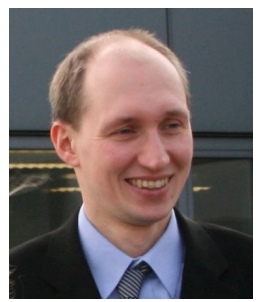

Jan Thimo Grundmann is a research engineer at DLR for $81 / 2$ years. He received a Diploma in Mechanical Engineering - Aerospace Engineering from the $R W T H$ Technical University of Aachen, Germany, in 2006. He works in the projects MASCOT, MASCOT2, GOSSAMER-1, GOSOLAR, and ROBEX. He supports system engineering in these projects, related studies, and at the DLR Bremen CEF on electrical topics. He is also pursuing system studies in planetary defence, spacecraft reliability and space project responsiveness.

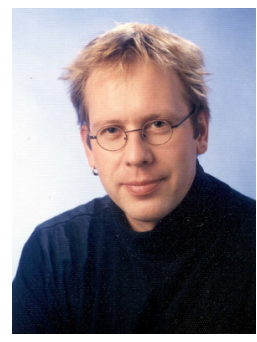

Jens Biele works as a senior staff scientist at DLR (German Aerospace Center) in Cologne, Germany. He is involved in the Rosetta Lander and HAYABUSA2 MASCOT lander projects as payload manager and scientist and has also been involved in a number of solar system exploration studies. Before his current position, he spent one year as a Postdoc with the Max-Planck-Institute for Chemistry in Mainz. He obtained his Ph.D. in 1998 in geosciences at the Free University Berlin while doing atmospheric research with the Alfred-Wegener-Institute for Polar and Marine Research. He studied experimental physics at the University of Kaiserslautern and at Imperial College, London. His field of special expertise is cometary science, regolith mechanical properties as well as probes, payloads and small systems, in particular landers, for missions to small bodies in the solar system.

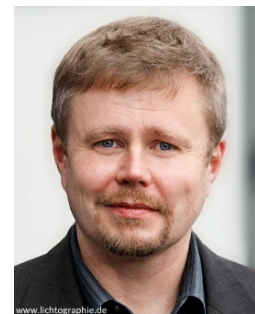

Dr. Bernd Dachwald is professor for astronautical engineering at $\mathrm{FH}$ Aachen University of Applied Sciences, Germany. He is project director for FH Aachen's IceMole project and lead of the Enceladus Explorer consortium. He is also adjunct lecturer for space systems engineering at RWTH Aachen University. Before his current position, he was mission operations director for SAR-Lupe at the DLR German Space Operations Center at Oberpfaffenhofen and postdoc mission analyst at DLR Cologne. In 2003, he obtained his PhD in aerospace engineering from the University of the Armed Forces Munich for low-thrust trajectory optimization with a novel method that involves neural networks and evolutionary algorithms. He has studied aerospace engineering at the University of the Armed Forces Munich and postgraduate business administration at the University of Hagen. His current fields of scientific research are space mission analysis, design, and optimization, intelligent methods for spacecraft trajectory optimization and attitude control, innovative space technologies (especially solar sails and subsurface sampling), solar system exploration (especially icy moons and small bodies), astrobiology, and planetary defense.

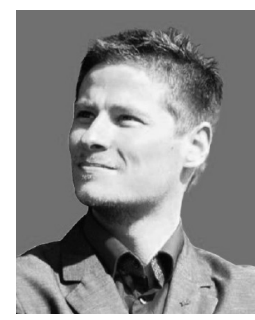

Christian D. Grimm is a research engineer at the German Aerospace Center (DLR), Institute of Space Systems in Bremen, Germany, where he started work in 2010. He received his Master degrees in Astronautics and Space Engineering from Cranfield University, UK, as well as 
in Space Technology from Luleå University of Technology, Sweden. During the MASCOT Project he functioned as Integration Lead as well as AIV/AIT Manager which he continues to assist the ongoing preparations of the landing mission in 2018. In addition, his activities concentrate currently on the system design, simulation and test of improved small body landers and their supporting mechanisms.

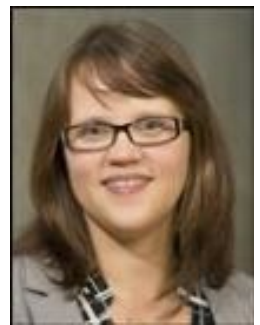

Caroline Lange is a research engineer in space systems engineering at the German Aerospace Center, Institute of Space Systems in Bremen, Germany, where she started working at the Department of Exploration Systems in 2008. Currently she is a system engineer in the MASCOT project as well as workpackage manager and system engineer for the ROBEX (Robotic Exploration of Extreme Environments) Helmholtz Alliance, where she is responsible for the design of a small generic instrument package for lunar applications. Caroline has an engineer's degree in Aerospace Engineering from the University of Stuttgart and is currently also pursuing her doctorate in space systems engineering.

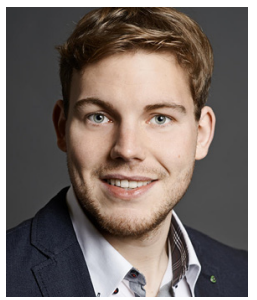

Jan-Gerd Meß obtained a Bachelor's degree in Computer Science at University of Paderborn, Germany, in 2013 and a Master's degree also in Computer Science at University of Oldenburg, Germany, in 2015, respectively. Being part of the scientific staff in the Institute of Space Systems of the German Aerospace Center (DLR) in Bremen, he is responsible for software and application development in the Horizon 2020 project MAMMOTH-UP. His research focus is on adaptive sensor data compression and self-configuring monitoring for spacecraft.

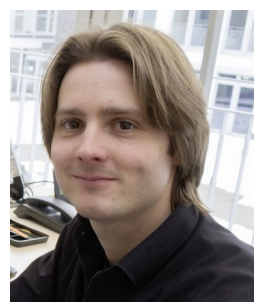

Patric Seefeldt is pursuing a Ph.D. at $D L R$ and the University of Bremen on Development and Qualification Strategies for Deployable Membrane Spacecraft Systems. He works in the projects GOSSAMER-1 and GOSOLAR at the DLR Institute of Space Systems in Bremen, Germany. He studied mechanical engineering at the RWTH Technical University of Aachen, Germany, where he worked as a research associate at the Institute of Structural Mechanics and Lightweight Design.

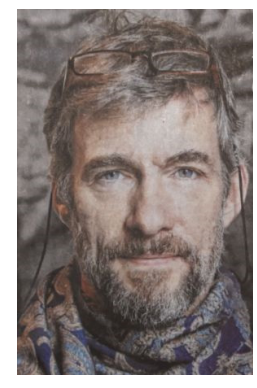

Peter Spietz is working on the technological development and adaptation of the membrane-based photovoltaics of GOSSAMER-1 for the project GOSOLAR at the DLR Institute of Space Systems in Bremen, Germany. He was project manager and system engineer of GOSSAMER-1 and the first DLR Research \& Development 'Kompaktsatellit' project, ASTEROIDFINDER/SSB for which he also led the Phase 0 competitive studies of the payloads CHARM and LIVESAT. Previously, he worked at the Institute of Environmental Physics (IUP) of the University of Bremen on the GOME ozone monitoring instrument series.

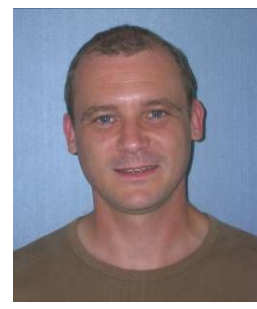

Tom Sproewitz is head of the department Mechanics and Thermal Systems of the DLR Institute of Space Systems since 2012. In 2001 he graduated at the Technical University Chemnitz, Germany with a Diploma in Applied Mechanics as part of Mechanical Engineering. After graduation he worked at the DLR Institute of Composite Structures and Adaptive Systems as mechanical engineer until 2009. He was involved in the development, manufacturing and mechanical testing of the ROSETTA-Lander PHILAE as Mechanical Analysis Engineer. Thermal analysis on porous sandwich structures for dish antennas on telecommunication satellites later became his field of competence. Since 2009 he works at the Institute of Space Systems in Bremen with focus on structures, mechanisms, deployment systems as well as environmental testing.

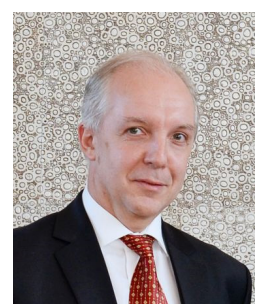

Stephan Ulamec has more than 20 years of experience in the development and operations of space systems and instruments. After finishing his Ph.D. at the University of Graz, 1991, he worked as a Research Fellow at ESA/ESTEC until 1993 and is since then at the German Aerospace Center, DLR, in Cologne. Besides of his activities in system engineering and project management of the ROSETTA Lander, PHILAE, he is engaged as payload manager of MASCOT for the HAYABUSA2 mission. He was involved in numerous studies for in-situ packages and landers for space research as well as the definition and performance of tests for various systems to be operated on planetary surfaces. 